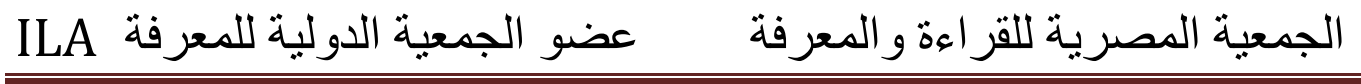

\section{استراتيجيات التعليم والتعلم الحديثة \\ أدب الخيال العلمي نموذجًا}

\author{
إعداد \\ دكتور / حسن شحاته \\ أستاذ المناهج بكلية التربية \\ جامعة عين شمس
}




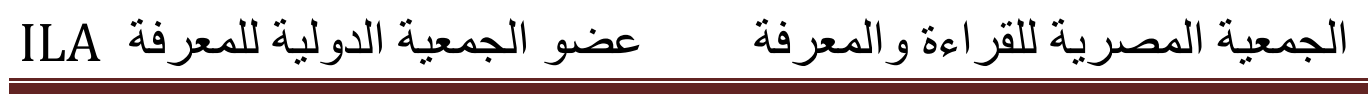




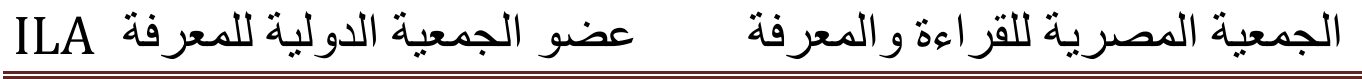

تعددت وتنوعت استراتيجيات التدريس، وتطورت باستخدام نظريات فاعلة وحديثة،

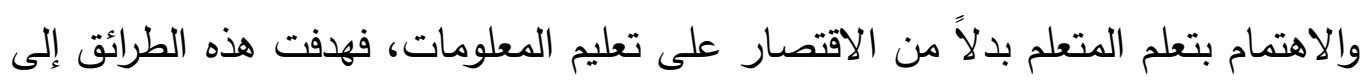
جذب انتباه الطالب عن طريق إثراكه في العملية التعليمية، إن الحاجة الملحة إلى مثل هذه الاستراتيجيات الجديدة، توجه مسار التعليم في العصر الحديث، نظراً للانفجار إلى

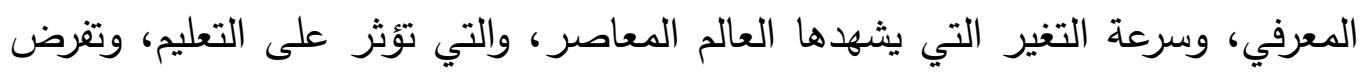
أعباء ومتطلبات على الأفراد لتتمية أنفهم، واكتساب المهارات التي ترفع من قدرتهم على ولى تونى رفع مستوى معيشتهم، والتواجد في مجتمع العولمة، وفي نشر مظلة التعلم والمعرفة باعتبارها حقاً من حقوق الإنسان مما يسهم في جهود التتمية المستدامة.

إن استخدام الخيال العلمي في التدريس أحد الأساليب التربوية المهمة، التي يشغف بها الكبار والصغار وهي من أقوى العوامل لاستثارة المتعلم في مختلف مراحل عمره ، فهو ميال إلى أدب الخيال العلمي سواء بسماعها، أو قراءتها، أو مشاهدتها، وذلك لأنها تجذبه، وتثحذ انتباهه، وتحفز دافعيته إلى التعلم، كذلك تعد أجناس الخيال العلمي

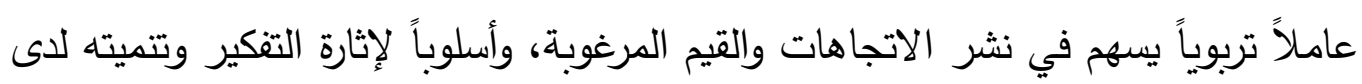
المتعلم.

وكثيراً ما تأتي قصة الخيال العلمي أو فيلم الخيال العلمي في مصاف أساليب الجذب، والتسلية، والاستثارة في أوساط المجتمع عموماً، وفي الوسط التعليمي على وجها

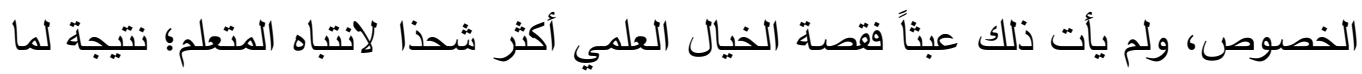
تتصف به من تأثير على مشاعر المتعلم الداخلية؛ نظراً لتسلسل أحداثها، ووقائعها المشيرة، وتحليقها في عالم آخر، ومما تجدر الإثارة إليه، أن تأثير الخيال العلمي ليس محصوراً على فئة بعينها، ولا مرحلة عمرية محددة؛ إنما ذات سيطرة مطلقة على مشاعر كل الفئات

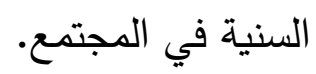




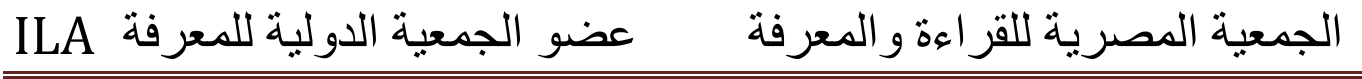

وبما أن الإستثارة سمة بارزة تميز الخيال العلمي ، فيتوجب داخل البيئة التعليمية

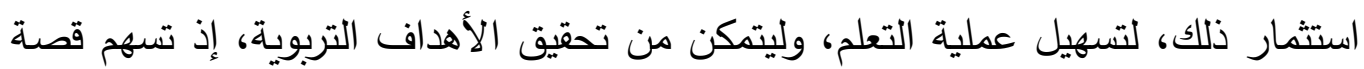
الخيال العلمي في رفد السامع أو القارئ بالمتعة، كما أنه تتيح للمتعلمين فرصة أكبر للفهح والاستيعاب، بما يحويه هذا الأسلوب من إغراء ينجم عنه نمو شخصية المتعلم وتطورها في الجوانب العقلية، والوجدانية معا.

ومن أهم الأمور التي تعمل على تدريب حواس المتعلم وتعليمه التفكير الإبداعي والخيال، وهما وسيلة طبيعية لتنمية التفكير، والتعلم، وذلك لما تتضمنه من عناصر

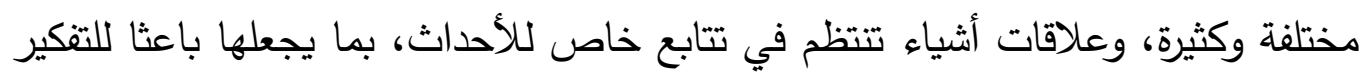
الإبداعي، والإبداع، بالإضـافة إلى أن التفكير التخيلي، إلا أن التفكير الخيالي يبقى سراً

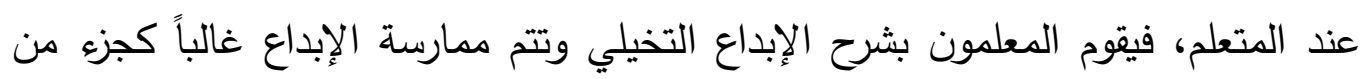

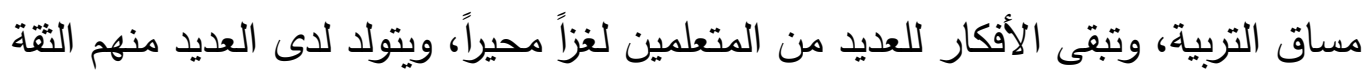
في إضافة مهارات هذا التفكير التي تمكنهم من إيجاد وتطوير أفكار خاصة بهم، وفي بعض الأمثلة، يتوقع من المتعلمين أن يتعلموا من خلال دارستهم لأعمال أدبية وعلمية وفنية الكثير من المفاهيم والقيم وينتجون إبداعات متتوعة.

إن التفكير الإبداعي هو أرقى أنواع النشاط الإنساني، فقد أصبح منذ الخمسينات

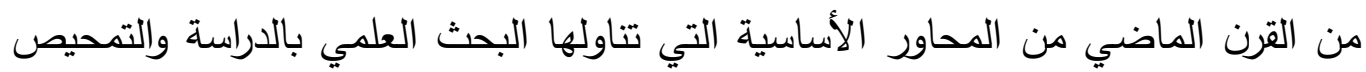
في عدد كبير من الدول المتقدمة منها والنامية، فالتقدم العلمي والتكنولوجي والحضاري الذي نشهده اليوم، يتطلب تفجير القدرات الإبداعية وتطويرها عند الفرد وكذلك فإن المشكلات الحياتية عن هذا التقدم، تحتاج إلى تفكير إبداعي ، للتغلب عليها، لذا فإنه يقع على عاتق جميع صانعي القرار، والمؤسسات التربوية، والقائمين على عملية التدري، العمل على رعاية مجالات الإبداع وتنميتها عند المتعمين. 


\section{1 - الخيال العلمي - المفهوم والنثأة:}

في أعقاب الطفرة الصناعية في أواخر القرن الثامن عشر إلى منتصف القئه القرن

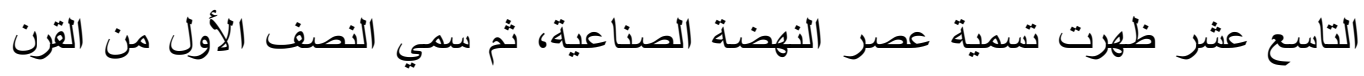

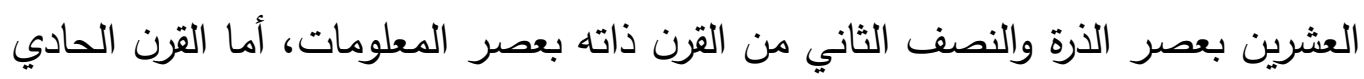

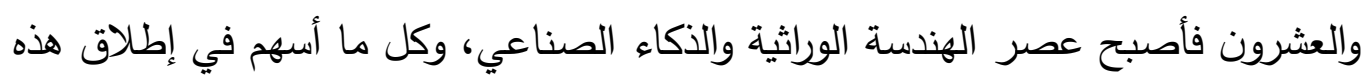

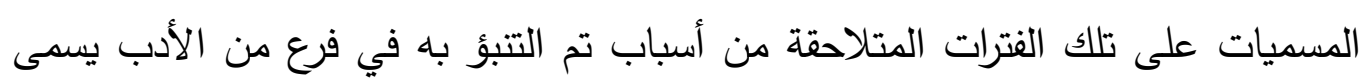

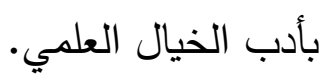

غير أن مفهوم الخيال العلمي ما يزال غامضاً، ففي حين يجزم بعضهم بأنه أدب التبا مغرق في القدم يصل إلى حد امتزاجه بالأساطير والخرافات، فإن بعضهم الآخر يرال يراه أدباً

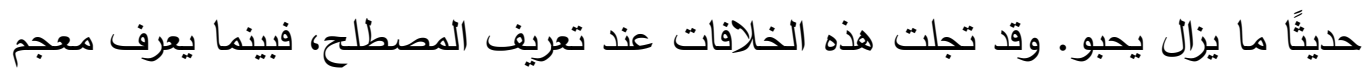

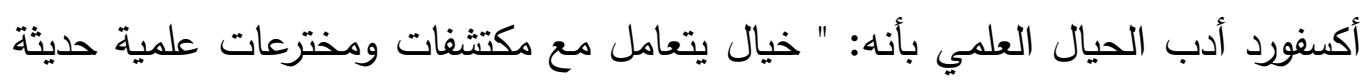

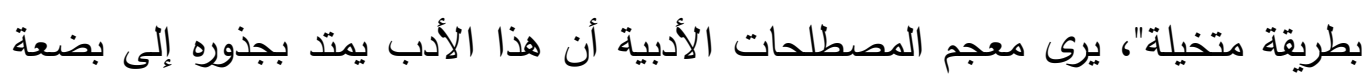

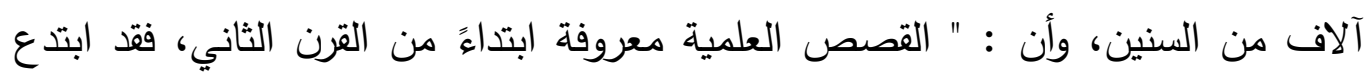

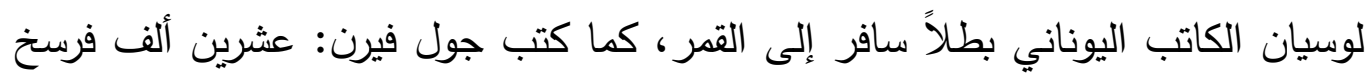

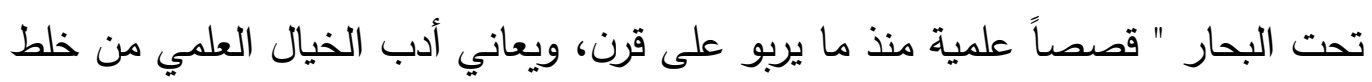
واضح بأنماط أخرى من التعبير الأدبي كالفتتازيا والأسطورة والخرافة.

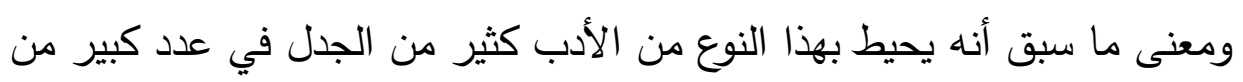

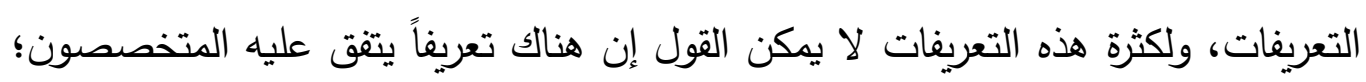

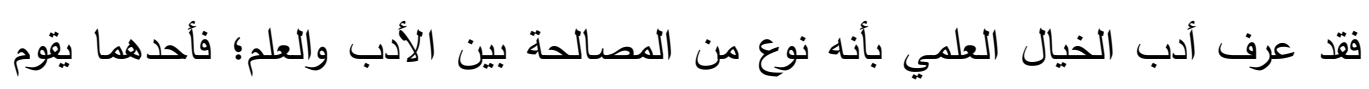

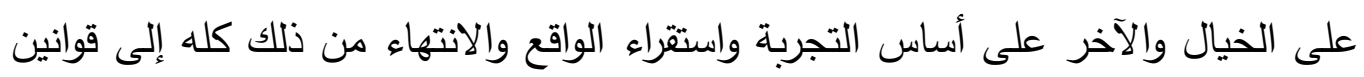

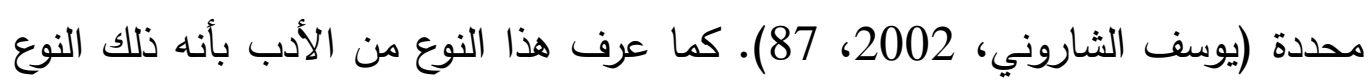

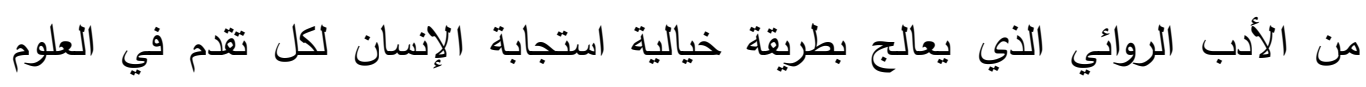

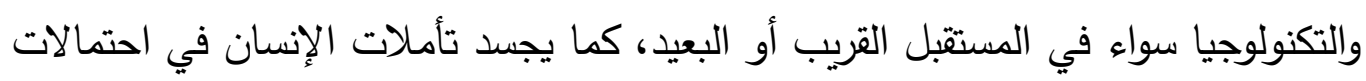




\section{الجمعية المصرية للقر اعة والمعرفة عضو الجمعية الدولية للمعرفة}

وجود حياة في الأجرام السماوية". ويصف الخيال العلمي بأنه تتاول للتقدم العلمي

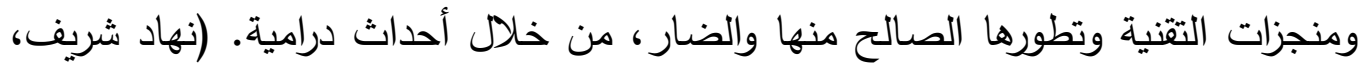
(111، 1997

إنه لم يأت المتخصصون في الغرب بتعريفات تختلف كثيراً عن تعريفات

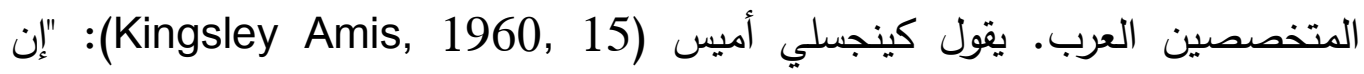

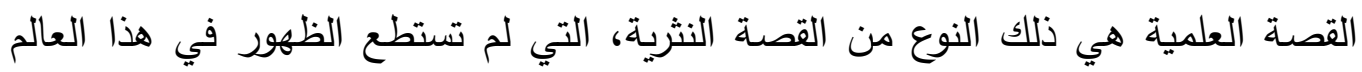

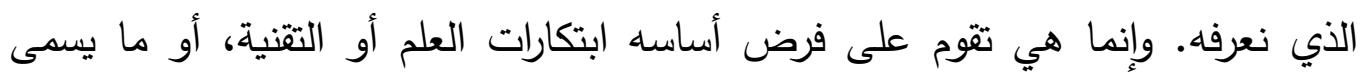

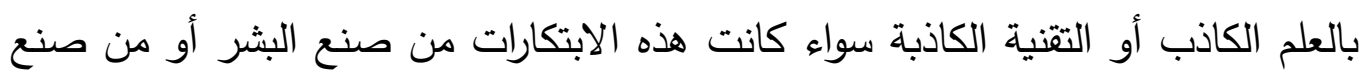

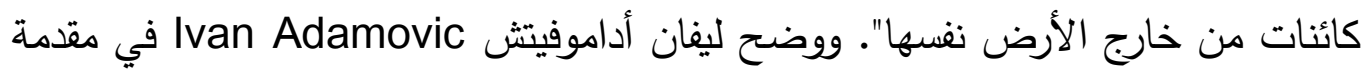

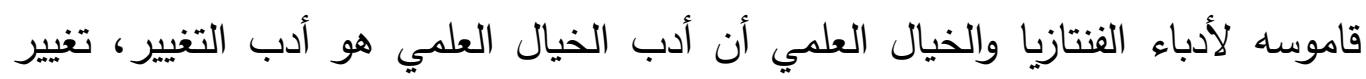

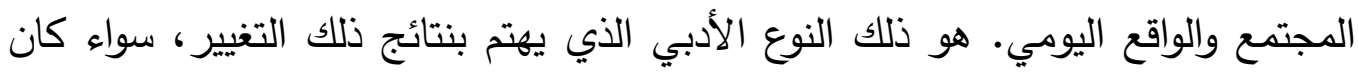

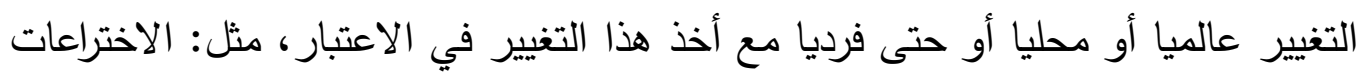
والتجارب العلمية والقدرات الخارقة للإنسان.

واختلف المتخصصون حول بداية هذا النوع من الأدب، رغم ارتباط أدب الخيال

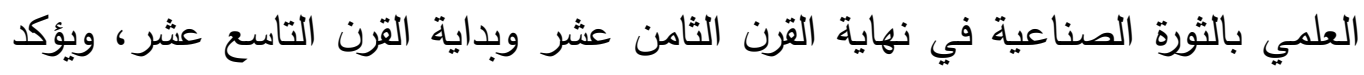

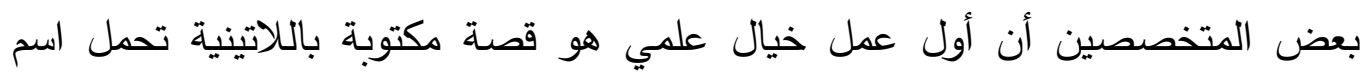
الحلم، كتبها عالم الرياضيات الألماني يوهانس كبلر Johanes Kepler عام المبل 1634،

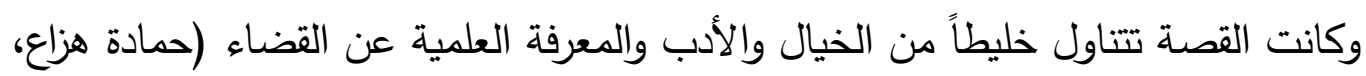
2014، 56)، كما أن الكاتب الفرنسي فونتنل Fontenelle هو أول كاتب لأدب الخيال

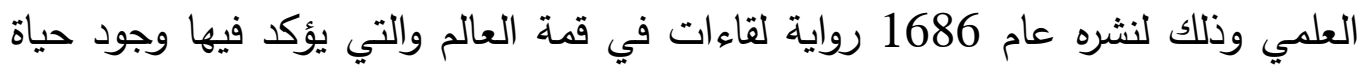

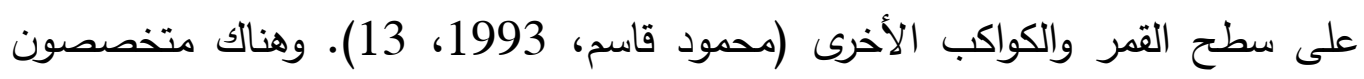

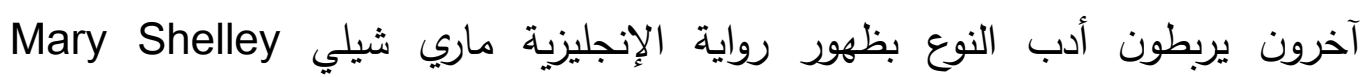

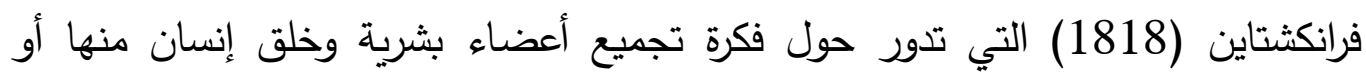




\section{الجمعية المصرية للقر اعة والمعرفة عضو الجمعية الدولية للمعرفة ILA}

بالأحرى خلق مسخ بشري ذي مصير بائس يشبه مصير بروميثيوس المحكوم عليه

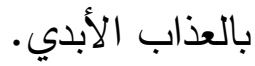

والجدير بالذكر أن غالبية الدراسات تؤكد ميلاد مصطلح أدب الخيال العلمي

Scientific إلى هوجو جرنسباك الذي استخدم عام 1922 مصطلح Science Fiction Fiction ث ثيره عام 1924 إلى Scientificion، وبعد عامين أسس أول مجلة لأدب ألى الخيال العلمي وهي مجلة قصص مذهلة Amazing Stories، ليستقر بعد ثلاثة أعوام،

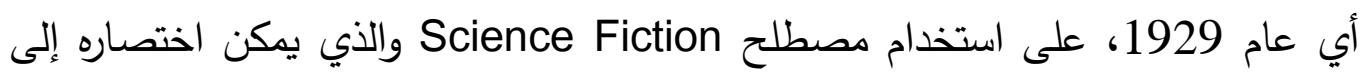
Sci-fi

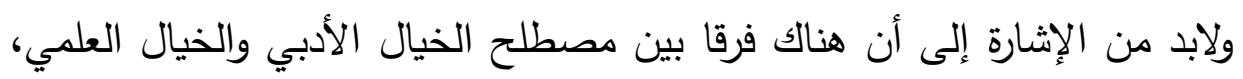

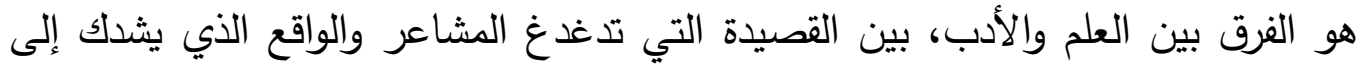

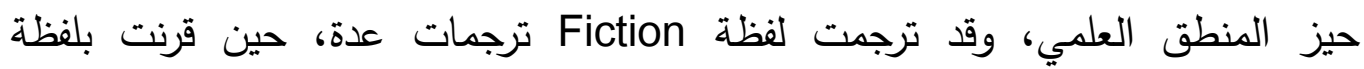
Science القصص العلمي التصوري - الرواية المستقبلية - رواية الخيال العلمي - أدب الخيال

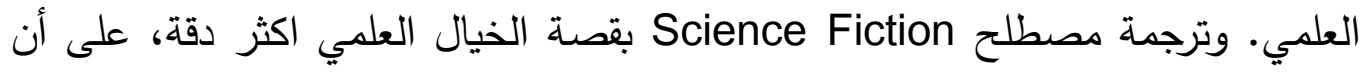
نفهم لفظة القصة بالمعنى الواسع، أي النثر القصصي، الذي يضم القصة القصة القصيرة

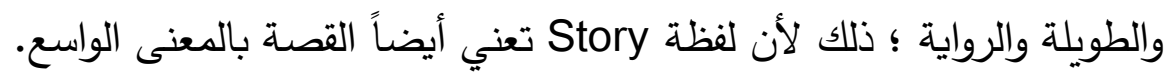
وهنالك عدة تعريفات لأدب الخيال العلمي منها: (حسن شحاته وليلى معوض، 2018،

تعريف معجم أكسفورد الوجيز Concise Oxford Dictionary أدب مملوء بالخيال، يقوم على اكتثافات علمية أو تغيرات بيئية مفترضة، ويعالج عادة رحلات الفضاء، والحياة على الكواكب الأخرى. 


\section{الجمعية المصرية للقر اعة والمعرفة عضو الجمعية الدولية للمعرفة ILA}

تعريف دائرة المعارف الأمريكية: هو أدب خيالي Fiction، يشكل فيه أحد المنظورات العلمية عنصرا في الحبكة أو الخلفية. تعريف دائرة المعارف البريطانية المصغرة Micropaedia: أن أدب الخيال العلمي يعالج أكتشافاً، أو تطوراً علمياً، سواء حدث في المستقبل أو في الحاضر الخيالي أو في الماضي المفترض، متفوقاً على ما هو موجود أو ببساطة مختلفا عنه.

وخلاصة ما سبق أن مصطلح الخيال العلمي يعتبر مصطلحاً حديثاً لصور شتى،

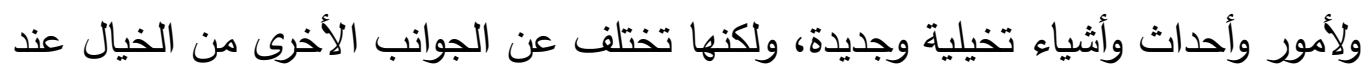
البشر بوجود أرضية أو أساس أو فكرة علمية مجردة.

2 - أنواع الخيال العلمي ووظائفه:

يقسم النقاد الخيال العلمي إلى نوعين: الخيال العلمي الجاف أو الخشن أو المنضبط Hard، والخيال العلمي الناعم Sofr. ويتميز الخيال العلمي الجاف بالاهتمام بالتفاصيل العلمية، يهتم بالعلوم الطبيعية (الفلك، الفيزياء، علم الجينات، البيولوجيا...)

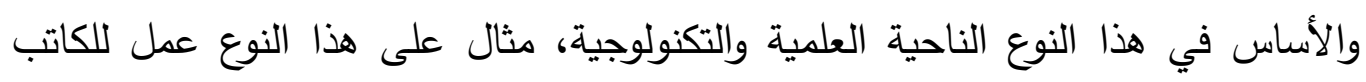
الأمريكي هال كليمينت (1953) بعission of gravity Clement بعنوان أيضاً رواية لخبير علوم الفضاء التشيكي كارل باتسنر Karel Pacner بعنوان رحلة إلى المريخ 1999/1998 وفيها يصف أول رحلة استكثافية لكوكب المريخ، مع سرد الكثير باتينر

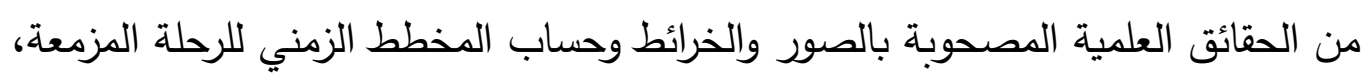

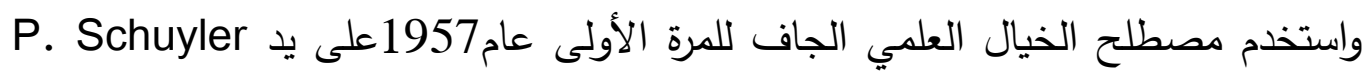
Miller

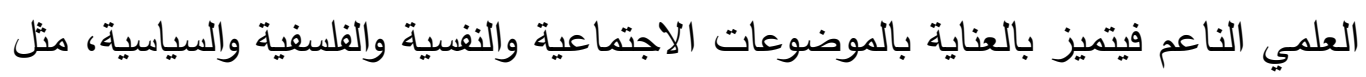

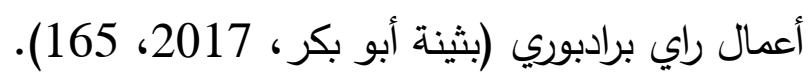




\section{الجمعية المصرية للقر اعة والمعرفة عضو الجمعية الدولية للمعرفة ILA}

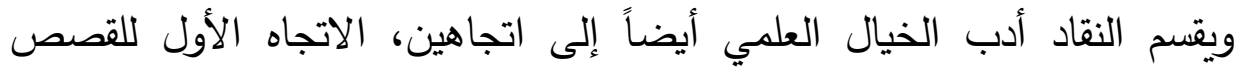

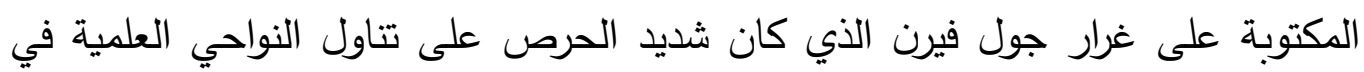
قصصه، وبذلك يكون فيرن مؤسس الاتجاه التكنولوجي المعنى بعالم الإنسان الخارجي.

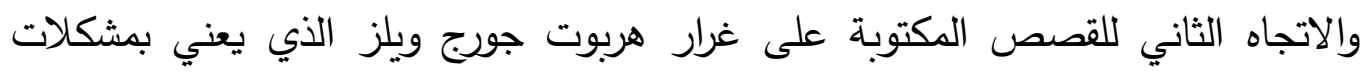
المجتمع والأفكار الفلسفية، وبذلك يكون ويلز مؤسس الاتجاه الفلسفي المعنى بعالم الإنسان الداخلي (يوسف الثاروني، 2002، 89).

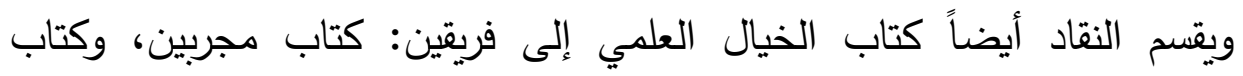

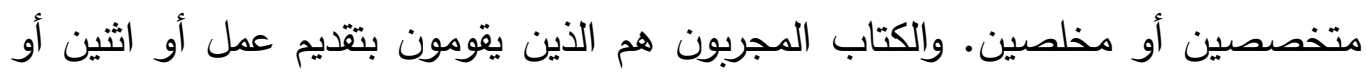

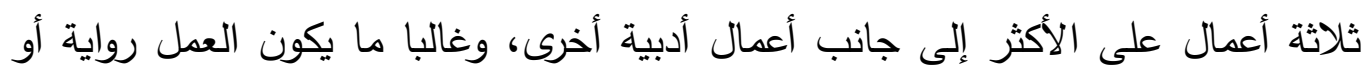

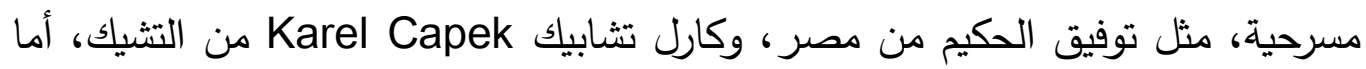
المتخصصون فهم مخلصون لأدب النوع ولا يكتبون غيره، ويكتبون القصة القصيرة والرواية والمسرحية، مثل نهاد شريف من مصر، وطالب عمران من سوريا ولودفيك سوتثيك لهاكيك

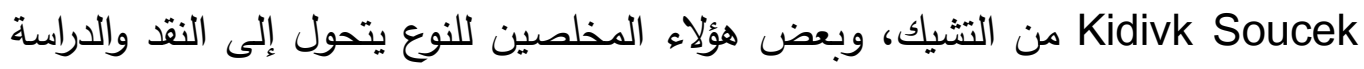

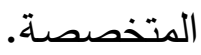

وفيما يتعلق بالثكل الأدبي الذي يقدم فيه الخيال العلمي، يمكن القول إن هذا

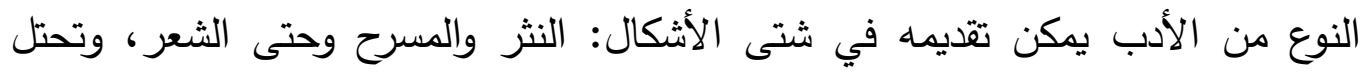

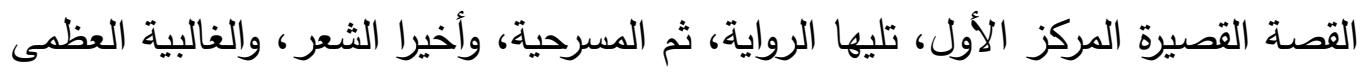

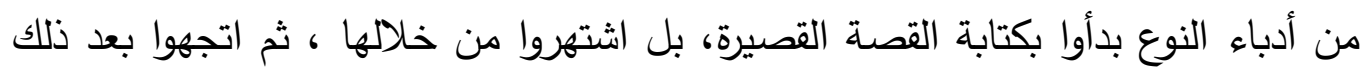

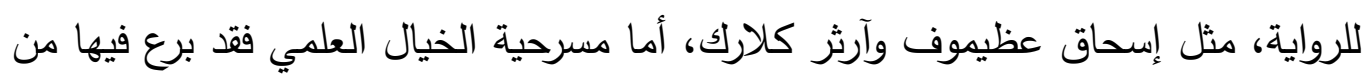

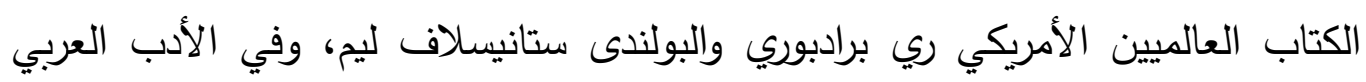
كتب توفيق الحكيم ثلاث مسرحيات، بالإضافة إلى بعض المسرحيات المتفرقة لبعض الدابل

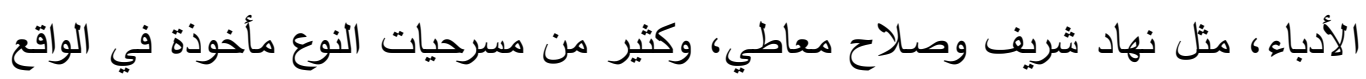

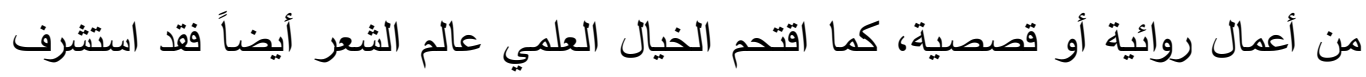




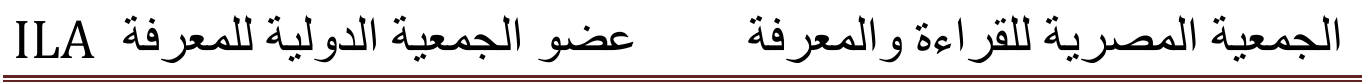

الثاعر الإنجليزي وليم وردزورث (1770-1850) William Wordsworth أدب Lyrical ballads الخيال العلمي في مقدمة كتابه المسمى قصص شعرية شعبية غنائية (1798)، وتضمنت الطبعة عام 1800 قصائد جديدة ومقدمة إضافية، وهناك أيضاً قصيدة خيال علمي للشاعر الفيتنامي ترنج خانه شنه بعنوان: مناظر طبيعية مصغرة (سكولز، 1996، 20) إنه في إطار هذا الموضوع يمكن تقسيم أدب الخيال العلمي فرعين: أدب الخيال العلمي المتفائل وأدب الخيال العلمي المتشائم، النوع الأول يحتفى بالتقدم التكنولوجي ويبحث عن حلول تكنولوجية لمشاكل الغد. أما النوع الثاني فدائماً ما يشير إلى الآثار السلبية الناجمة عن التطور التكنولوجي وهم ممثلو الخيال العلمي المتشائم ويتاولون في قصصهم المشكلات المستقبلية المحتملة، يضعون في المقام الأول الخطر

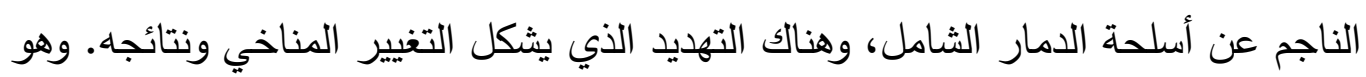
مصدر إلهام لكثير من الأدباء، ومن الكوارث التي قد يسببها التغيير المناخي أو كما وهن يسميه البعض الاحتباس الحراري: ارتفاع مستوى مياه البحار، والتصحر، وذوبان ثلوج القطب الثمالي، وانتشار أمراض جديدة، واندلاع الحروب على الأراضي الصالحة للزراعة.

وللخيال العلمي ثلاث وظائف جوهريه: وظيفة دعائية، ووظيفة تحذيرية نقدية، ووظيفة تتبؤية، ودائما ما نجد الكثير من أعمال أدب الخيال العلمي تروج لاختراعات العلم الحديثة، بل إن الكثير من المتخصصين يرون في أدب الخيال العلمي راعيا رسميا للعلم

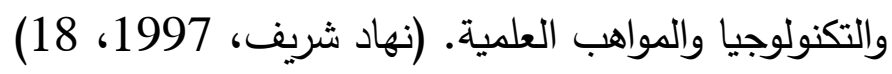

وهناك أعمال أخرى في أدب الخيال العلمي تقوم بوظيفة نقدية تحذيرية ؛ تنقد عيوب المجتمع وتحذر من التأثيرات المحتملة للتقدم التكنولوجي على الجنس البشري، وفي مثل هذه الأعمال عادة ما يطرح الكاتب سؤال: ماذا يحدث لو ....؟ (ماذا يحدث لو

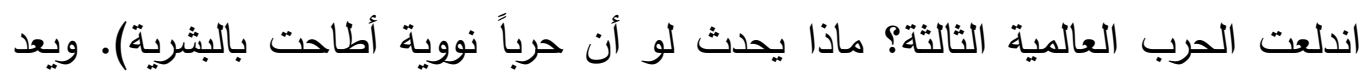
برادبوري الممثل الأبرز لهذا التيار التحذيري. 


\section{الجمعية المصرية للقر اعة والمعرفة عضو الجمعية الدولية للمعرفة}

وهناك أيضاً مجموعة أخرى من قصص الخيال العلمي تقوم بالتتبؤ بالمستقبل

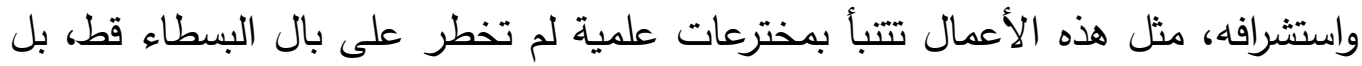

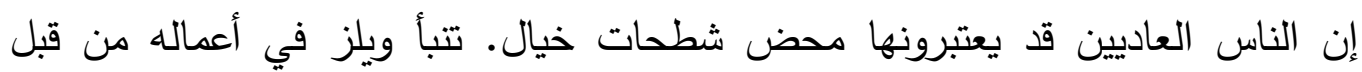
بأسلحة خطيرة مثل الطائرة والدبابة والغازات السامة، فظهرت هذه المخترعات لإنات لاحقا في

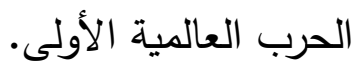

3 - - الخيال العلمي وأخلاقيات العلم:

ذلك أن الخيال العلمي هو في حقيقته رؤية للعالم لا يرى التقدم العلمي إلا بما

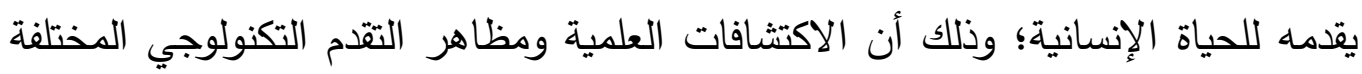

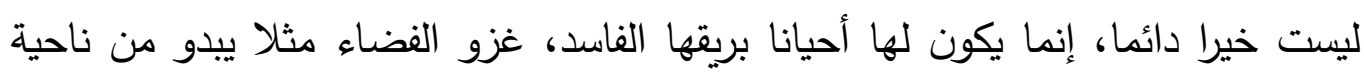

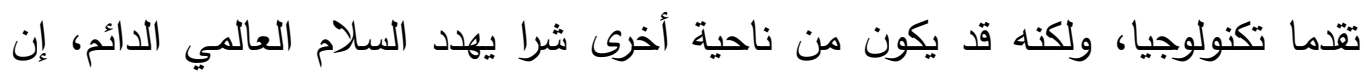

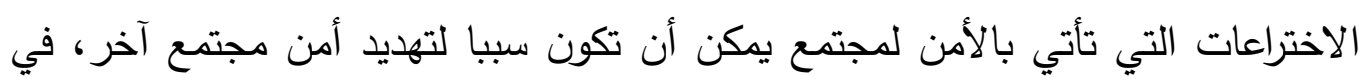

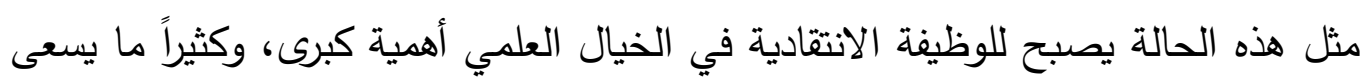

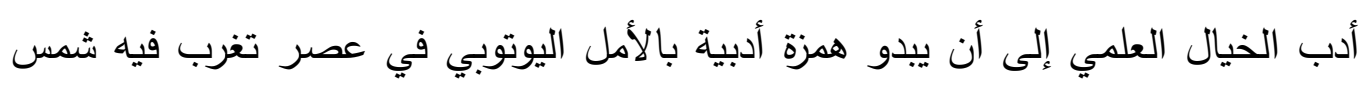
اليوتوبيا.

لم يقف كتاب الخيال العلمي هذا الموقف الانتقادي وحدهم ـ لقد شاركهم فيه كثير

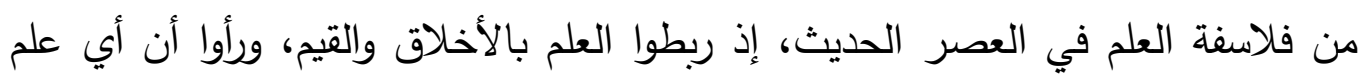

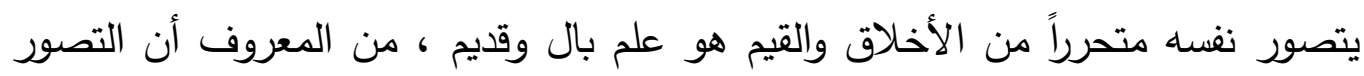

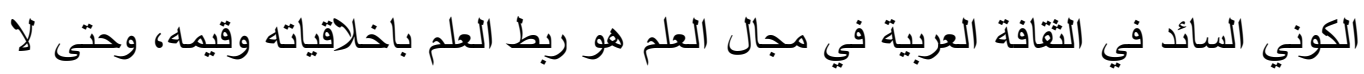

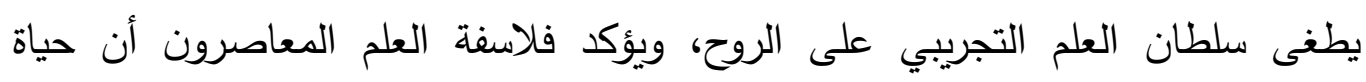

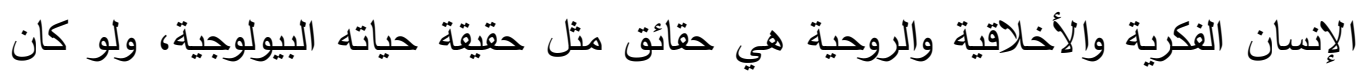

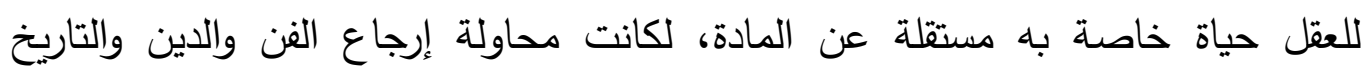

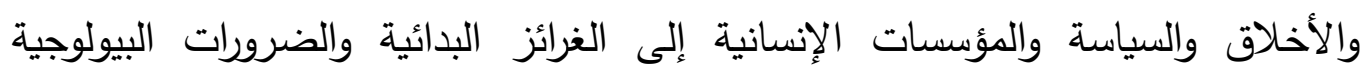




\section{الجمعية المصرية للقر اعة والمعرفة عضو الجمعية الدولية للمعرفة}

برنامجاً لا أمل في تحقيقه، ولكن من شأن الإصرار عليه أن يعزلنا عن فهم الإنسان فهما

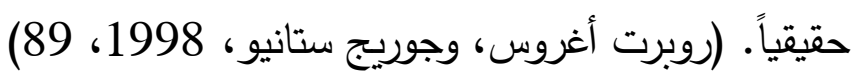

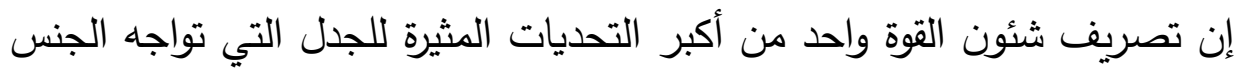

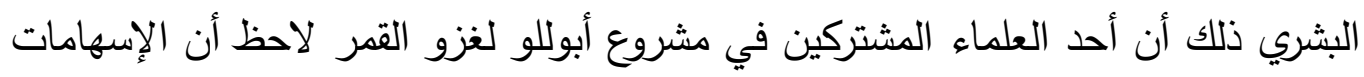

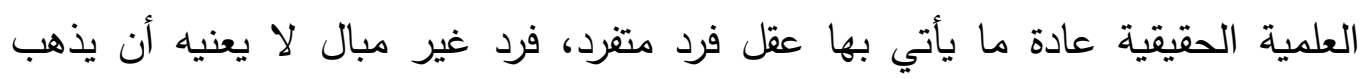
الجميع إلى الجحيم. (لينداجين سيفرد، 2004، والحروب النووية والبيولوجية ومسئولية العالم الخلقية قارب نحن جميعا فيه بدرجات الفيات

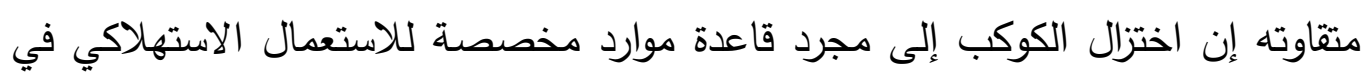
المجتمع الصناعي الآن بنزلة تدهور روحي ونفسي، مثل هذا الاتجاه الكضاد للتقدام التكنولوجي عبر تخريب العالم الطبيعي مما يتوافق عليه كتاب الخيال العلمي المعاصرين التهني وفلاسفة العلم ومنظرو أخلاقيات الأعمال والبيئة الطبيعية.

4 - معايير أختيار قصص الخيال العلمي (حسن شحاته وليلى معوض، 2018، 349): قصص الخيال العلمي ذات أهمية خاصة بالنسبة للأطفال وبالنسبة للناشئة أيضا،

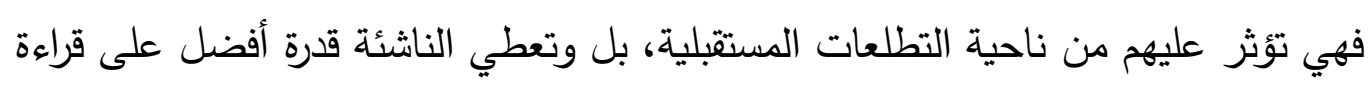

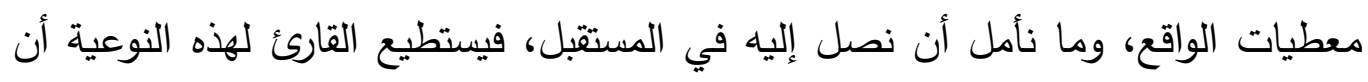

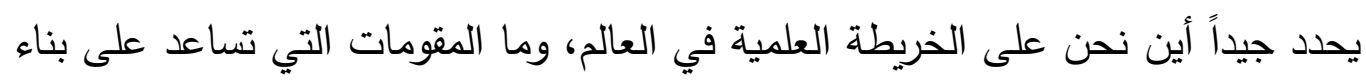

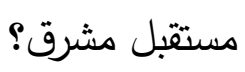

ولكي تسهم هذه القصص في بناء الفكر وبناء العقل والقدرة على التنكير المنظم،

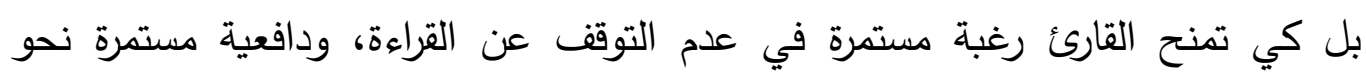

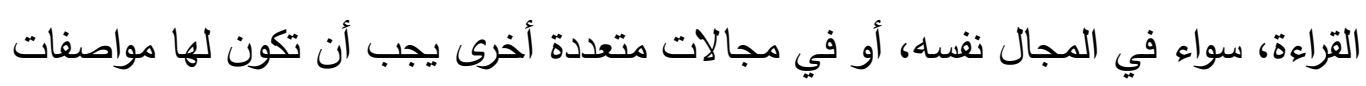

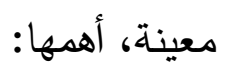




\section{ILA الجمعية المصرية للقراءة والمعرفة عضو الجمعية الدولية للمعرفة}

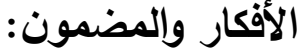

- أن تحتوي هذه النوعية من القصص على أفكار مناسبة للسن، التي تخاطبه من مرحلة الطفولة حتى مراحل العمر الأخرى. - أن تكون هذه الأفكار مشوقة ومثيرة لعقلية القارئ. - أن تحتوي على مصطلحات علمية مناسبة للفئة العمرية المخاطبة لها. - أن تكون الأفكار في نطاق الخيال المبني على العلم، لا الخرافات والأساطير. - أن تكون هذه الأفكار دائما قابلة للتنفيذ والبناء في المستقبل. - أن تحتوي هذه الأفكار على صورة جمالية وبلاغية وألفاظ جديدة ومبتكرة. - أن تقدم هذه الأفكار مواقف، تدعو القارئ إلى الإبداع وإلى الابتكار. - أن تجعل القارئ دائما قيد الأحداث، فيكون هو القارئ والبطل. - أن تجعل القارئ دائما في محاولة للبحث عن حلول ، لما تفرضه القصة أو الرواية العلمية من مشكلات.

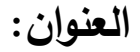

- أن يكون العنوان سهلاً وبسيط الألفاظ. - أن يحمل العنوان كما من التشويق والتساؤلات حوله. - أن يكون عنوانا معبرا عن مضمون القصة. - أن يحمل العنوان رسالة يريد غرسها قدر الإمكان. 


\section{ILA الجمعية المصرية للقر اءة والمعرفة عضو الجمعية الدولية للمعرفة}

\section{اللغة : الغ}

رغم أننا أمام قصص خيال علمي، تتنمي للعلوم ربما قدر انتمائها للأدب، إلا أننا في النهاية نتحدث عن أدب، فالعلوم مجالها المعامل وبين الأجهزة والمختبرات، ولكننا هنا لنابكيا أمام أدب فني ثري، قصصيا أو روائياً، ولذلك ينبني: نئ

- - أن تكون الألفاظ المستخدمة مناسبة للمرحلة العمرية التي تخاطبها. - - البعد عن المصطلحات العلمية غير المفهومة. - - البعد عن الألفاط المبتذلة والعامية. - الاهتمام باختيار اللفظ والتتويع بين الأساليب المستخدمة. الثكل العام للقصة: - الثقام

- - أن تكون الرسومات والصورة جذابة، وتخدم موضوع القصة الفئة العمرية. - - أن تكون الأحداث والأفعال وأشكال الصراع مقبولة ومعقولة، إلى حد ما. - - أن يكون عدد الثخصيات مناسبا. - أن تعتمد قصة الخيال العلمي، في الخروج من المواقف الصعبة، على العقل والتفكير السليم. - أن تعتمد على أسلوب الحوار أكثر من السرد. - أن يكون الحوار بين الثخصيات طبيعيا، لا تتاقض فيه. - أن تحبب التلاميذ في القيم الحميدة، وتتفرهم من القيم المذمومة. - - أن تكون القصة متتوعة الأهداف تربوياً، اجتماعيا، وخلقيا. ولكي تحقق قصص الخيال العلمي أهدافها، لابد من اختيار هذه القصص بعناية، والتخطيط لاستخدامها داخل الصف، وتدريب المعلم على طريقة تدريسها للتلاميذ. 


\section{الجمعية المصرية للقر اعة والمعرفة عضو الجمعية الدولية للمعرفة}

وهناك قائمة بمعايير اختيار قصص الخيال العلمي، متمثلة في تلك القصص؛ إذ

$$
\text { يجب أن: }
$$

- تكون قائمة على مفاهيم علمية، تمتد وتستكمل عن طريق الخيال القائم في فرضيات مدروسة يمكن تحقيقها، والبعد عن الفنتازيا، التي مصدرها الحدس

$$
\text { والتخمين والخرافة. }
$$

- ت تضمن أكبر عدد ممكن من المفاهيم العلمية، أو تتطوي على ثراء للمحتوى، أو المرتبطة بموضوعات وقضايا مرغوب فيها علمياً. - أن تتسم بالحتمية مة والحبكة والروائية، وأن تحترم عقل القارئ، وأن تتفاعل كل عناصرها مع بعضها البعض. - تتميز ببساطة الأسلوب وصحة اللغة وسهولة فهم الهصطلحات العلمية

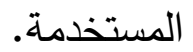
- - تكون قائمة على فكر ومنجزات وتصورات العلم وأدق مساراته. 5 - أهمية الخيال العلمي في التدريس:

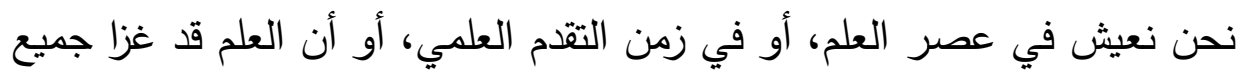

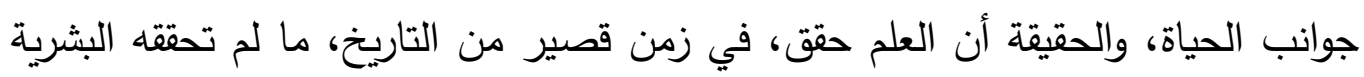

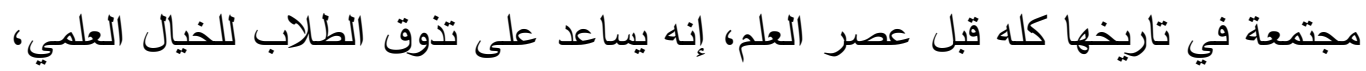

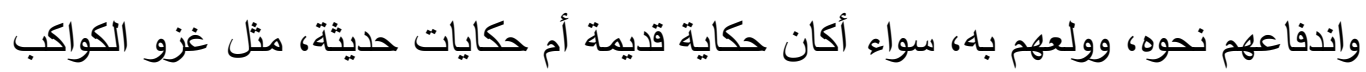
والفضاء الخارجي، بما يتضمن من كائنات مختلفة، يفيد للغاية في تتمية ملكات الطالب التابل

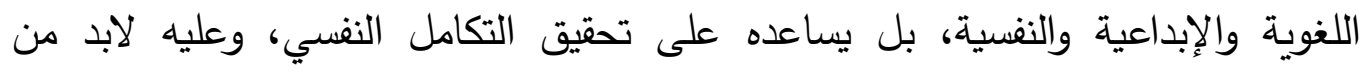

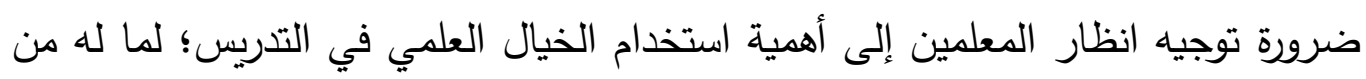
دور كبير في تحقيق النتائج التعليمية، لذلك لم يعد من المنطقي أو الطبية الطيعي أن يظل 


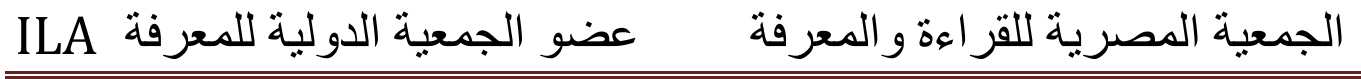

أطفالنا بعيدين عن كل ما يدور حولهم من تقدم علمي، وما هو منتظر أن يشهده العلم الحديث في السنوات القادمة، فلابد من إعدادهم لمواجهة كل المتغيرات والتطورات العلمية، لهئ وهم متسلحون بسلاح العلم والمعرفة؛ ليكونوا قادرين على الفهم والخلق والإبداع والتعامل مع لغة العصر ومستحدثات التكنولوجيا والتطوير، ومن هنا كانت الحاجة إلى أدب الخيال العلمي؛ ليسهم في إعداد الفرد إعداداً إيجابياً في المجتمع، بحيث يأخذ مكانه، ويشق ومن هنات طريقه، ويعرف دوره، ويكون مستعداً لتحمل مسؤولياته الاجتماعية.

وقد أكدت دراسة تيرنس وكاثي (Terence \& Cathy, 2004, 3) على أن استخدام الخيال العلمي، في أثناء التدريس في غرفة الصف، يساعد على: - زيادة الميول العلمية لدى التلاميذ وتطويرها. - - تحسين اتجاهات التلاميذ العلمية نحو العلم.

- - تمية فهم التلاميذ لعمليات العلم والعلاقة بين التخصصات العلمية المختلفة. - تحسين مواقف التعلم الحقيقية، وجعل العملية التعليمية مثيرة وممتعة للمتعلمين، مما يسهل تذكر المعلومات التي درسوها. وبمراجعة الأدب التربوي تبين أن الخيال العلمي استخدم في العملية التربوية فكانت نتائجه مثمرة، عن طريق استخدامه في تطوير أساليب متنوعة لتنمية النشاط العقلي سواء تم تنشيط التخيل كنشاط تلقائي مستقل أو من خلال أنشطة البرامج الدراسية، يتم من فن فئن خلال معلم غير نمطي يساعد على خلق مناخ التتوع والتكامل المستمر بين ما هو غير

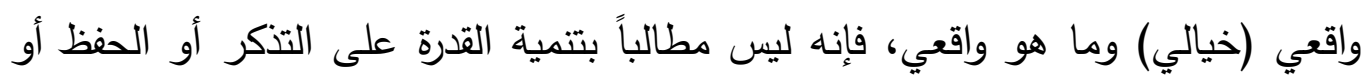
الفهم بل تنشيط عنصر الخيال في عملية التعلم من خلال تحقيق التكامل بين عناصر الذاكرة، وعناصر الخيال الذي يمكن أن يطلق لدى الفرد الحالة الإبداعية.

إنه يمكن التدريس باستخدام الخيال العلمي من خلال العلوم الطبيعية والاجتماعية والفنون من مداخل تدريس الخيال العلمي كتدريسه بواسطة التركز على إلقاء الروايات 


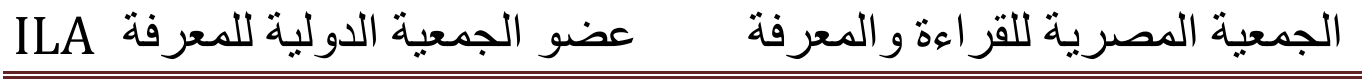

المتعلقة بالخيال العلمي، وتدريسه بواسطة مقرر أفكار في الخيال العلمي "ويهدف إلى توظيف قصص الخيال العلمي في صورة درامية تعبر عن المشكلات المعاصرة، ويمكن تدريسه باستخدام "المدخل التاريخي" ويهدف إلى دراسة ماهية الخيال العلمي، وتتبع نموه تاريخياً. ويمكن التدري بالخيال العلمي بعدة استراتيجيات على راشد (2010) هي:

1. استراتيجية راوي الحكايات: الراوي هو ذلك الشخص الذي يقوم بعرض قصة أو رواية من روايات الخيال العلمي أمام مجموعة أطفال لينمي فيهم ذلك الخيال، مستخدما في ذلك معرفته الجيدة بموضوع الرواية وقدرته على امتاع المستعمين والمشاهدين له وجذب انتباههم، والتأثير فيهم بصوته وتعبيرات وجهة ونظرات عينيه الثاقبة وإيماءات رأسه وجسمه وحركات ذراعية وكتفيه وأصابعه، فهو جيد في فن الإلقاء والتمثيل ويستعين ببعض المؤثرات التي تشير التشويق والمتعة. 2. استراتيجية مشاهدة أفلام الخيال العلمي يتبعها جلسات سيمنار: يتم اختيار الأفلام المناسبة لأعمار التلاميذ، في المحتوى التعلمي، وبعد مشاهدته تكون جلسة النقاش حول الفكرة ومدى ارتباط فيه بالخيال، ومدى إثارته، مثل: فيلم (رحلة إلى منتصف

$$
\text { الأرض)، وفيلم (قاهر الزمن). }
$$

3. جلسات عصف ذهني لإنتاج أفكار غير مألوفة: تستخدم لدراسة مشكلة موضوع ما، فيه تجتمع مجموعة من الأفراد ليصلوا إلى حلول أصيلة خلال المناقثة وطرح الحلول والبدائل وتفاعل الأداء والتوصل لأكبر عدد من الأفكار وليس مناقثة الآراء أو نقدها. 4. استراتيجية لعب الأدوار والتحدث مع شخصيات غير مألوفة: لعب الأدوار هي طريقة تربوية تفاعلية تعتمد على نشاط التلميذ التمثيلي وخصائصه في اتقان لعبة التثثيل من 


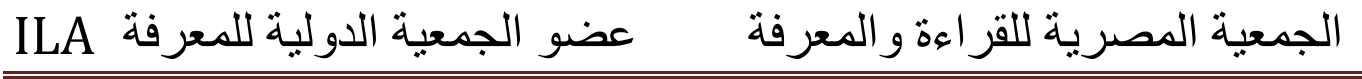

تفاعل وتلقائية، كما تعتمد على اختيار الموضوع وتوزيع الأدوار على التلاميذ من أجل تحقيق الأهداف التربوية، مثل: حوار بين صياد سكك وحورية بحر نصفها العلوي فتاة ونصفها السفلي سمكة وقعت في شبكته.

5. استراتيجية استكمال بدايات مطروحة وبناء درامي على نهايات معطاه في قصص الخيال العلمي تتنقسم إلى استراتيجيتين: الاستراتيجية الأولى تعتمد على استكمال بدايات مطروحة في قصص خيال علمي، يقدم المعلم لكل تلميذ قصة قصيرة من نوع نهاية مفتوحة بحيث لا تكون القصة كاملة بل يعطي بدايات لها تستعرض الفكرة وبعض الثخصيات خاصة الرئيسة في القصة وبعض المواقف، ثم يطلب من التلميذ قراءة البدايات وكتابة نهاية مناسبة للقصة، أما الاستراتيجية الثانية استراتيجية فرعية تعتمد على نهايات معطاة في قصص خيال علمي، يقدم المعلم للتلميذ نهاية قصة قصيرة من قصص الخيال ويطلب منه كتابة مناسبة لهذه القصة تتقق مع نهاياتها المعطاة، هذه الاستراتيجية تتمي لدى التلاميذ القدرة على الاستنتاج والتفسير والتخيل. وإذا كان من المتوقع أن قراءة قصص الخيال العلمي تكون فاعلة في التعليم والتعلم، إلا أنه يتوقع أن تتأثر هذه الفاعلية باستراتيجية قراءة قصص الخيال العلمي؛ حيث دعت عديد من الدراسات إلى تتوع استراتيجيات تناول قصص الخيال العلمي؛ فمنها من اقترح إجراء مناقثات وتكليف التلاميذ بمهام وتعيينات تعتمد على قصص الخيال العلمي

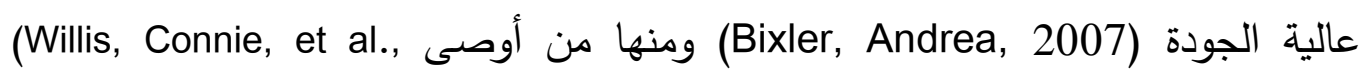
(Raham, R. Gary, 2004)(1999) بضرورة تنوع أسلوب توظيف الخيال العلمي المستخدم داخل الفصل لتحقيق الأهداف المنشودة، كما أشارت نتائج بعض الدراسات إلى أهمية (Cavanaugh, Terence W., مصاحبة قصة الخيال العلمي بنشاط من أنشطة القراءة 


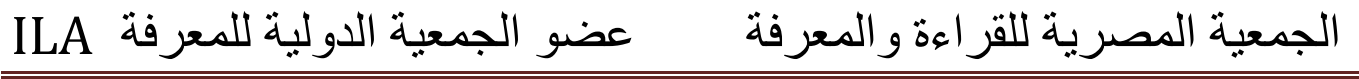

(Barnett, Michael \& Kalfka, Alan, 2007) و Cavanaugh, Cathy, 2004)

و (أمال بدوي، 1996)، و (أيمن حبيب ، 2000)، و (Cavanaugh, Terence, 2002).

وإذا كان توظيف أدب الخيال العلمي في تعليم المواد الدراسية وتعلمها فإنه سيكون

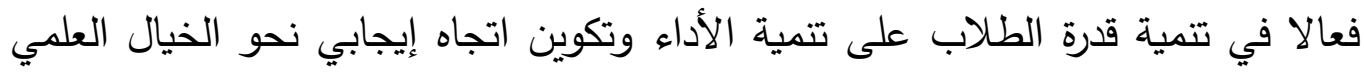
لانسجامه مع الأساليب التي تتمركز حول التلميذ وخصائصه العقلية والمعرفية والنمائية ونمط تعلمه المفضل، فمراعاة نمط تعلم التلميذ يساعد المعلمين على إعداد الخبرات

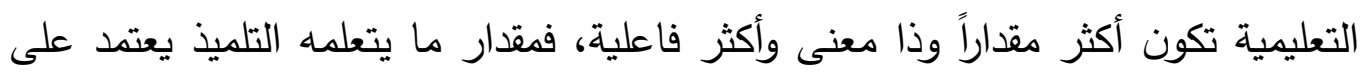

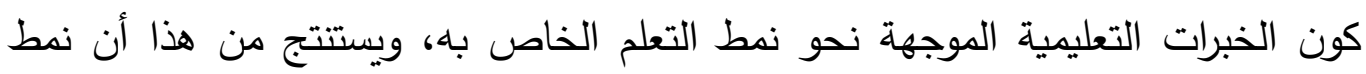

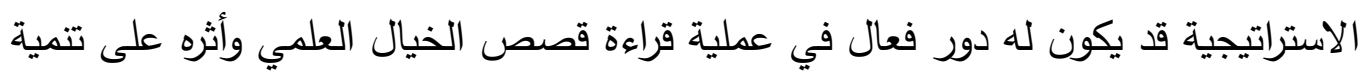

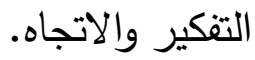

ولذا أصبح من الضروري البحث عن أساليب تدريس تتمركز حول المتعلم وخصائصه العقلية، والمعرفية، والنمائية، ونمط تعلمه الأفضل حيث أصبح توظيف هذه التها

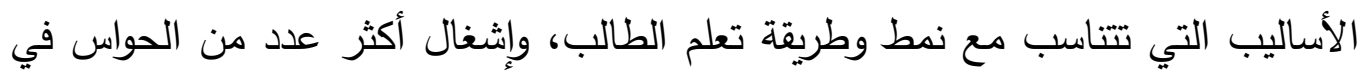
أثناء تعلمه ضرورة تربوية، كما يعمل على توفير خبرات تعليمية تراعي مستوى الاستعداد

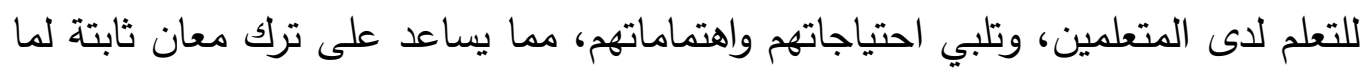
يكتسبونه من تعلم نتيجة مرورهم بهذه المواقف والخبرات التعليمية.

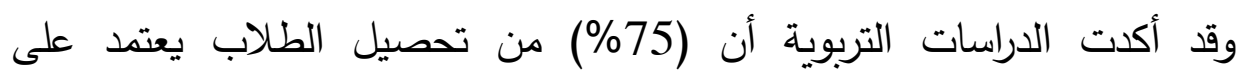
المتعمين أنفسه، وأن (25\%) من تحصيل الطلاب يعود إلى المعلم (حسن زيتون،

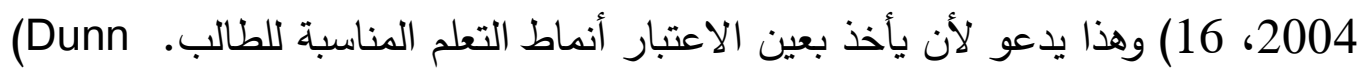

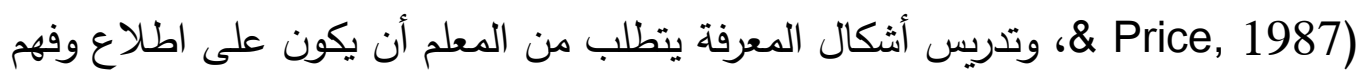

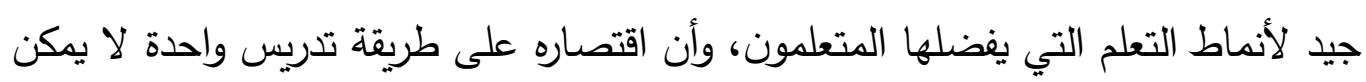
أن تكون ذات فاعلية لأنواع مختلفة من المتعلمين . 


\section{الجمعية المصرية للقر اعة والمعرفة عضو الجمعية الدولية للمعرفة}

ولو نظرنا إلى مفهوم نمط التعلم عند العديد من التربويين لوجدنا أنه يحمل

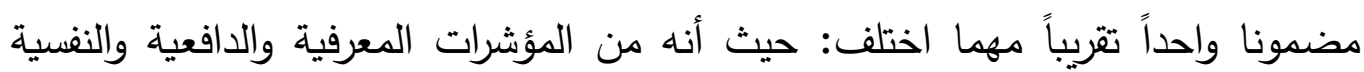
والمزاجية التي تعكس عملية استقبال المتعلم للمعلومات. وكيفية معالجته لها والتفاعل معها، وكيف يستجيب لها على نحو إيجابي من خلال بيئة التعلم.

وبين جريجور Gregore أن نمط التعلم هو مجموعة من الأداءات الميزة للمتعلم

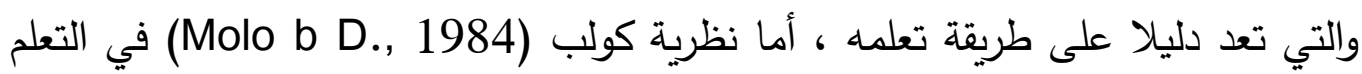

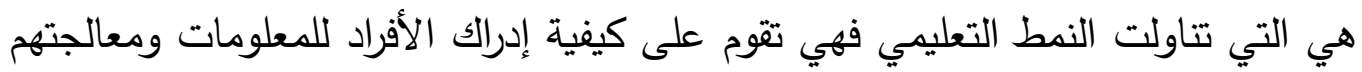

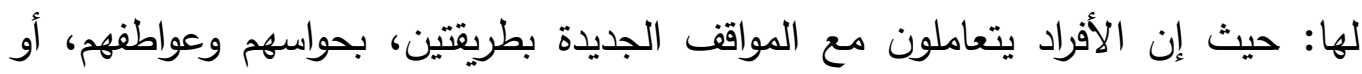

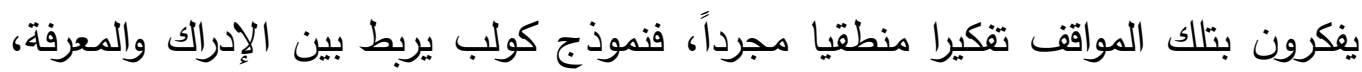

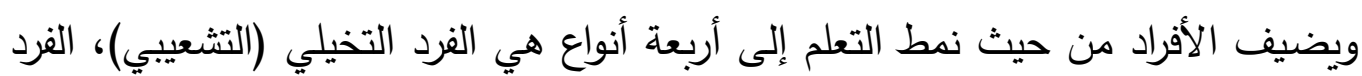
المنطقي (التمثيلي)، الفرد العملي (التجميعي)، الفرد التتفيذي (الاستيعابي). وتعرف استراتيجية قراءة قصص الخيال العلمي على أنها إجراءات قراءة قصص ومناقتتها بهدف إكساب القدرة على اكتساب وتتمية التعبير ، ويتم ذلك من خلال قراءة قصص الخيال العلمي ثم مناقثة المتعلمين في: أهم ثلاثة أحداث موجودة بالقصة.

دور العلم والعلماء في حل المشكلة الأساسية التي تدور حولها أحداث القصة.

سرعة التطور العلمي والتكنولوجي المحتمل وتأثيره على حياة المتعلم مستقبلاً.

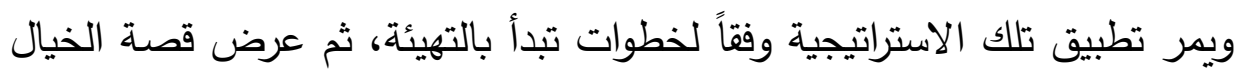
عن طريق الفلم أو قراءة قصة الخيال العلمي، ثم ربط التعبير بما ورد بقصة الخيال العلمي. 


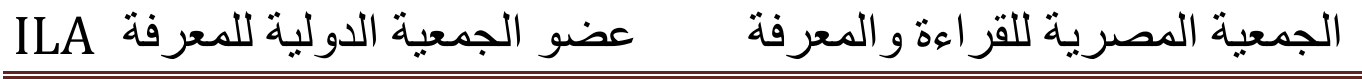

إن استخدام الخيال العلمي في قاعة الصف يحتاج استرجاع المتعلمين لخبراتهج العلمية الواردة في الرواية ثم سماع الرواية وممارسة مجموعة من الأنشطة العقلية العلمية؛ كالتفسير ، والاستنباط، والتوقع للنتائج المستقبلية (42-Julie E. Czereda, 2006, 41). واستخدام الخيال العلمي في غرفة الصف لابد وأن يواجه المتعلمين بتشكيلة من روايات الخيال العلمي بالمقالات العلمية: ليكونوا قادرين على استيعاب اندماج العلم في الرواية، قادرين على مناقثة الحقائق العلمية دع السماح لهم بكتابة رؤيتهم عن الخيال العلمي. (David A., Katz, 1999, 1)

إن استخدام الخيال العلمي في التدريس مصحوباً بأنشطة ينفذها المتعلمون في ضوء ما تعلموه من حقائق علمية بالدرس، وما تعلموه من الخيال العلمي يساعد في توفير (Marco S. Casar, تعليم ممتع وحقيقي يساعد في فهم بنية الظواهر الطبيعية وتطورها .el els., 2000, 99)

وإن الخيال العلمي يستخدم في التدريس لتعليم مفاهيم العلم، وتقريب المفاهيم المجردة والنظر في نتائج العلم والتقنية على مجتمعنا، وتدريب المتعلمين على الطريقة العلمية وتحفيز التفكير، وتعلم الاستتباط والنظر في التطورات المحتملة ونتائج التطورات

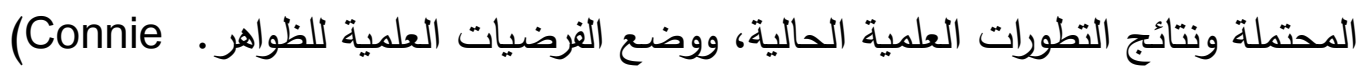
(Zoreaa, 1995) ، Willis, el els, 1999, 1-2) وأكدت دراس روايات الخيال العلمي في تتمية التفكير التخيلي من خلال تدريس اللغة الإنجليزية لدى طلاب المرحلة الثانوية المكسيكيين، في حين توصلت دراسة (Mary, 1997) إلى إقبال الأطفال في

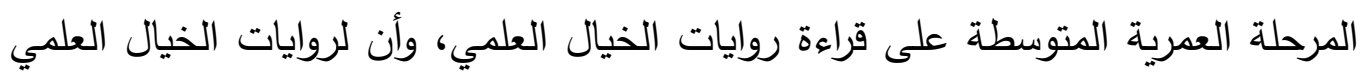
دوراً كبيراً في تتمية خيالات الأطفال وتتمية شخصياتهم بصفة عامة، وأكدت دراسة (شاكر عبد الحميد، 1998) على علاقة الخيال بكل من الإبداع وحب الاستطلاع في المرحلة الابتدائية، وتوصلت دراسة (أحمد عمران، 1998) إلى أن قصص الخيال العلمي المنشورة 


\section{الجمعية المصرية للقر اعة والمعرفة عضو الجمعية الدولية للمعرفة}

(Fifa, في مجلات الأطفال ساهدت في تنمية المفاهيم العلمية لديهم، كما توصلت دراسة (1999 إلى فاعلية رسومات وأفلام الخيال العلمي في تنمية العاهية مهارات القراءة والكتابة الثقافية البصرية ، وزادت من إيجابية المتعلمين في قاعة البحث. إن استخدام الخيال العلمي في التدريس يساعد على:

عقلنة خيال المتعلم وترقيته وضبطه، وتعزيز الجوانب الإيجابية فيه وتهذيب

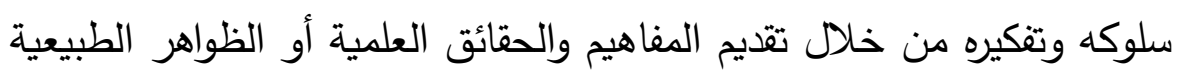
والمواقف المرتبطة بها بموضوعية تجذب التلميذ وتقنعه بما تتضمن. تلبية حاجات المتعلم إلى البحث والمعرفة والاكتثاف، وميله للمغامرة العقلية، وفضوله لمعرفة ما يجهله من خلال الإجابة عن كثير من الأسئلة التي تثغله

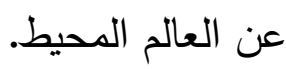
توسيع آفاقه العلمية المعرفية من خلال تزويده بالمعلومات والتفسيرات العلمية المنطقية لما يحدث وما يمكن أن يحدث من ظواهر علمية. تتمية الثقافة العلمية بأسلوب مشوق جذاب وممتع، يجعلهم أكثر إثارة وتفاعلاً وإعجابا بما يقرؤه. التأكيد على العلاقة بين الكائنات الحية ومنها البشر والظواهر الكونية والمكتثفات العلمية والمختراعات والآثار الناجمة عنها.

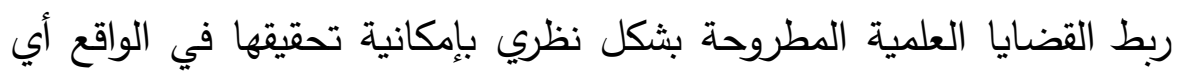
تقديم العلم في إطار تطبيقي.

ويرى (Cavanaugh, Cavanaugh, 2004, 5) أن افلام الخيال العلمي لا

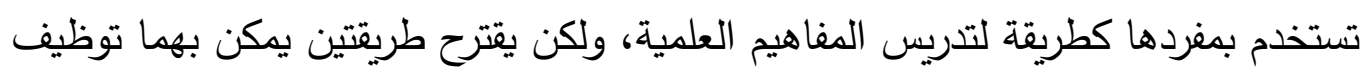
الخيال العلمي في التدريس، هما: 


\section{الجمعية المصرية للقر اعة والمعرفة عضو الجمعية الدولية للمعرفة}

\section{- - - - كنشاط استهلالي:}

حيث يعرض الفيلم في بداية الدرس، ليعمل على إيجاد الميل المبدئي للموضوع

المراد تدريسه، والذي قد يكون غير مألوف لديهم.

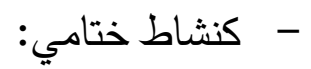

حيث يعرض الفيلم في نهاية الدرس؛ ليكون موضوعاً للمناقثة لتعزيز الحقائق المتعلمة في الدرس، ويمكن اعتباره نقطة بداية لمزيد من البحوث في موضوع الدرس. وقد اقترحت دراسة (رجب عبد الحميد وإيمان نويجي، 2009) طريقة لتوظيف

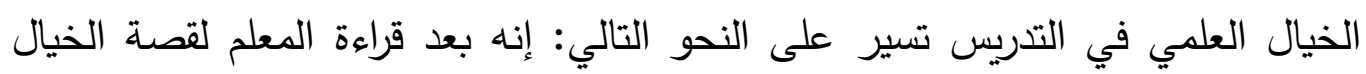

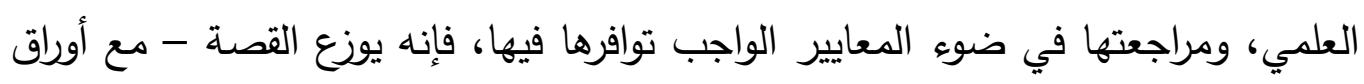

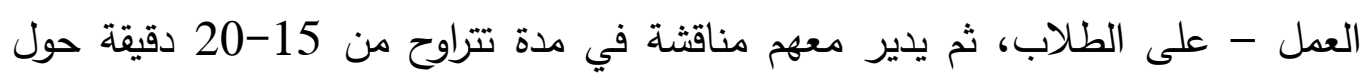

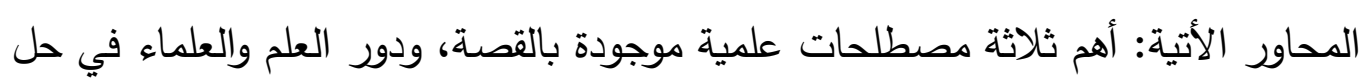
المشكلة الأساسية التي تدور حولها أحداث القصة، وسرعة التهاثة التطور العلمي والتكنولوجي ولئي المحتمل وتأثيره على حياة الطالب مستقبلا.

وقد قارنت الدراسة بين أثر اختلاف استراتيجية قراءة قصص الخيال العلمي (قراءة

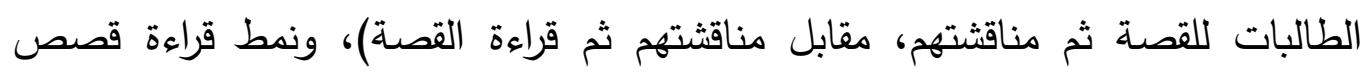

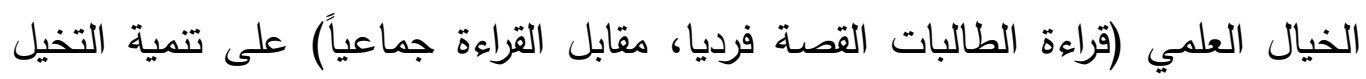

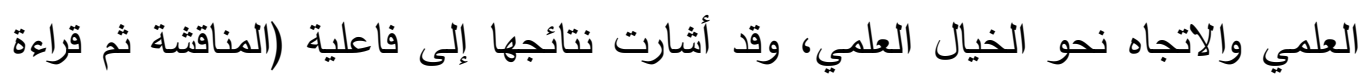
القصة - القراءة الجماعية) في تتمية التخيل العلمي لاى الطالبات، ولكن لم يتغير الاتجاه نحو الخيال العلمي باختلاف استراتيجية القراءة أو نمط القراءة. وقد اقترحت دراسة (جمال السيد، 2013) طريقة تدريس تقوم على استخدام روايات الخيال العلمي في تعليم الظواهر والموضوعات الجغرافية، تتم وفق خطوات، تبدأ

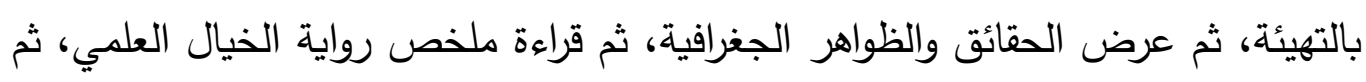




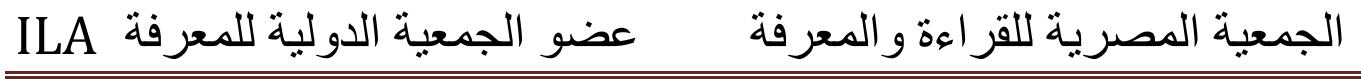

ربط الحقائق والظواهر الجغرافية بالدرس بما ورد برواية الخيال العلمي ثم تتفيذ مهام صفية عقلية في ضوء رواية الخيال العلمي.

يتضح مما سبق أن استخدام الخيال العلمي في التدريس لله أهمية فهو يساعد على تهلى تحقيق أهداف تعليمية ومنها تتمية التفكير والقدرات الذهنية، ويوسع آفاق المتعلمين ويحسن الجو التدريسي العام كون الخيال العلمي محبب للمتعلمين، ويساعدهم على التعرف على التطورات المحتملة للظواهر والتفكير في احتمالاتها المستقبلية وتأثيرها على الحياة سطح

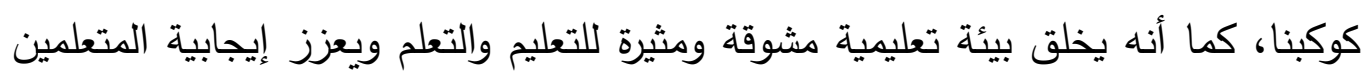
ومشاركتهم في عملية التعلم. 6

بالإضافة إلى طرق التدري، التي يمكن أن يستخدمها المعلم لتنمية الخيال

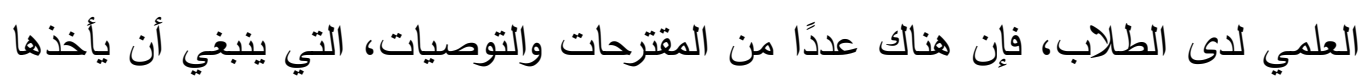

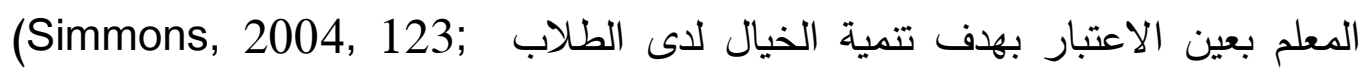

$$
\text { : NASA, 2001, 8) }
$$

تشجيع الطلاب على قراءة كتب ومجلات وقصص الخيال العلمي.

تشجيع الطلاب على القراءة العلمية الحرة والكتابة العلمية الخيالية.

توفير بيئة تعليمية حرة، تشجع الطلاب على إبداء الرأي والتفكير الاحتمالي،

$$
\text { بعيداً عن النمطية. }
$$

استخدام الأسئلة المثيرة والمحفزة لاختيار المعارف العلمية للى الطلاب. التتويع في طرق التدري، والتركيز على الطرق المعتمدة على حل المشكلات والاستقصاء والاكتشاف. تشجيع الأفكار الجديدة والمفاجئة والغربية. 


\section{الجمعية المصرية للقر اعة والمعرفة عضو الجمعية الدولية للمعرفة}

تدريب الطلاب على الملاحظة الدقيقة، وتتمية الفضول العلمي وحب

الاستطلاع.

$$
\text { تشجيع الألعاب العلمية والخيالية. }
$$

توجيه التلاميذ نحو مواقع إلكترونية على الثبكة الدولية للمعلومات، تتضمن

موضوعات عن الخيال العلمي.

تشجيع التأليف والكتابة، والاختراعات لدى الطلاب.

تكليف الطلاب، خاصة الهواة، بتأليف أو كتابة أفكار في مجال الخيال

العلمي.

تشجيع الطلاب على متابعة أفلام ومسلسلات الخيال العلمي.

ويذكر يعقوب نشوان (1993، 38) أن الخيال يرتبط ارتباطاً وثيقاً بالإبداع، فكل

منهما مصطلح معقد، ولكنهما يتفاعلان مع بعضهما معا كعمليتين منفصلتين، فالتخيل عملية عقلية، تحدث في عقل الفرد لتصور شيء ما بناء على الخبرات الماضية، أما الإبداع فهو دمج المعرفة والخبرات السابقة بصورة، لم تكن معروفة للفرد من قبل؛ فالتصور والتخيل يؤديان دورًا مهماً في اكتشاف الطريقة، التي يتم بها دمج المعرفة والخبرات السابقة، في حل المشكلات واقتراح الحلول المناسبة.

ولا شك أن الخيال عندما يرتبط بالعلم، فهو يعمل على وضع حلول لمشكلات قابلة للتنفيذ، ويبعد عن الشطط والتوهم، فيكون الإبداع الناتج من دمج المعرفة مع الخبرات السابقة مصبوباً في قالب الممكن.

وتتبع أهمية قصص الخيال العلمي، من حيث إنها تعني بتربية الخيال عند

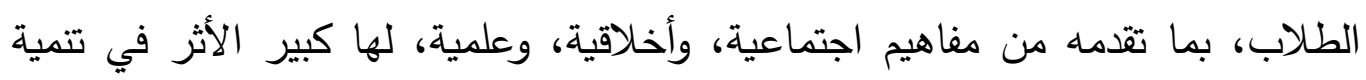
الطلاب خلقياً وجمالياً وانفعالياً، وفي صقل مشاعرهم المرهفة، وتوسيع إدراكهم بالبيئة 


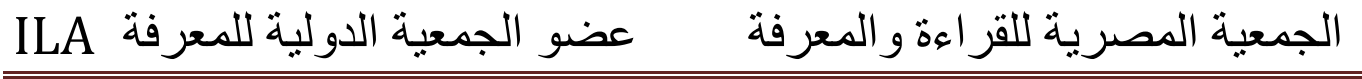

المحيطة، وزيادة ثروتهم اللغوية، ومخزونهم الفكري والمعرفي، وخلق التحدي لديهم لدفعهم لاقتحام المجهول. (Zoreaa M., 1995, 42) 7 - سلبيات الخيال العلمي وكيفية التغلب عليها:

يرى بعض العلماء أنه بالرغم من اهتمام المشاهدين بأفلام الخيال العلمي نتيجة المشاهد الغرببة فيها، قد يدفع الشباب الصغير إلى دراسة العلوم، فإنه لديهم قلق منها؛

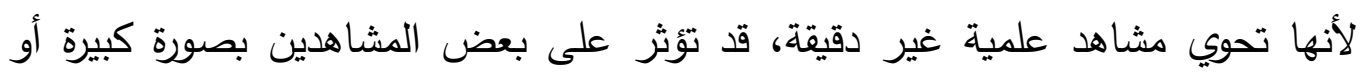
صغيرة، حيث لا يستطيعون التمييز بين الحقيقة والخيال في تلك الأفلام. فقد أشارت نتائج دراسة (Barnstt, Michael, et al., 2006) إلى أن المشاهدة الفردية لأفلام الخيال العلمي، قد يكون لها تأثير سلبي على أفكار الطلاب الخاصة بالظواهر الطبيعية، فعلي سبيل المثال عند مقارنة طلاب المرحلة المتوسطة الذين شاهدوا فيلم The Core بالذين لم يشاهدوا الفيلم، كان لديهم عدد من المفاهيم الخاطئة عن علوم

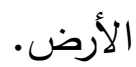

وللمدرسين كيفية استخدام الخيال العلمي (قصص وأفلام) بطرق مختلفة في الفصل، مثل: قراءة القصة ثم عمل مناقثة جماعية في الفصل، أو تقسيم الطلاب إلى مجموعات لمناقثة السيناريوهات التي استخدمها المؤلف في القصة، كما يمكن طرح مجموعة من الأسئلة العلمية حول القصة، وذلك لاكتثاف المعلومات الخاطئة أو الناقصة في القصة.

كما صممت دراسة (Laprise, Winrich, 2010) مهاماً مكتوبة في ثلاثة مقررات لمدة عام يستخدمها الطلاب بعد مشاهدة مجموعة من أفلام الخيال العلمي المختلفة، للقيام بنقدها من ناحية الدقة العلمية. 


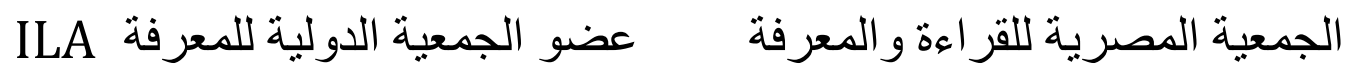

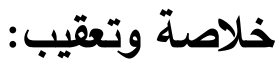

1. الخيال العلمي استراتيجية تدريسية تساعد على زيادة الخيال المستقبلي لدى المتعلمين، وتحسن مواقف التعليم والتعلم، وتحقق الإثارة والمتعة.

2. الخيال العلمي قسمان هما الخيال العلمي الجاف الخشن الذي يهتم بالتقاصيل العلمية في العلوم الطبيعية والتكنولوجية، والخيال العلمي الناعم الذي يهتم بالموضوعات الاجتماعية والنفسية والفلسفية والسياسية. 3. للخيال العلمي وظائف أهمها: الوظيفة الدعائية، والوظيفة التحذيرية النقدية، ولئه

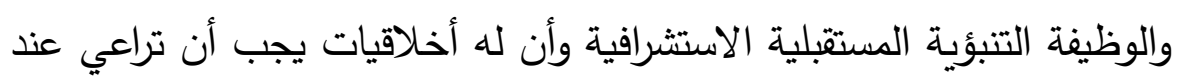
تقديمه للمتعلمين.

4. هناك معايير يجب أن يتم الاسترشاد بها عند اختيار قصص الخيال العلمي

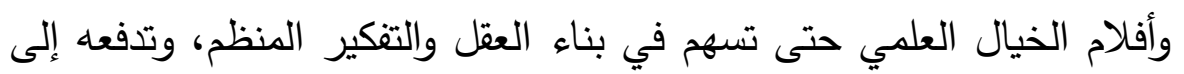

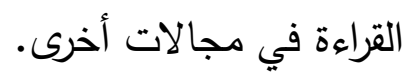

5. تدريس الخيال العلمي له عدة استراتيجيات منها: راوى الحكايات، ومثاهدة

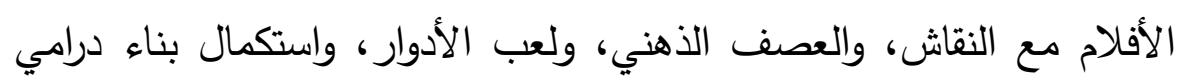
ونهايات مفتوحة وأن للمعلم أدواراً متعددة غايتها تتمية قرارات الخيال العلمي وليدي

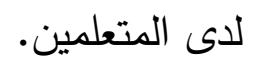

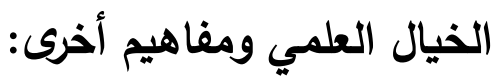

هناك مفاهيم في ميدان الأدب تتقاطع وتتداخل مع مفهوم الخيال العلمي. وعليه

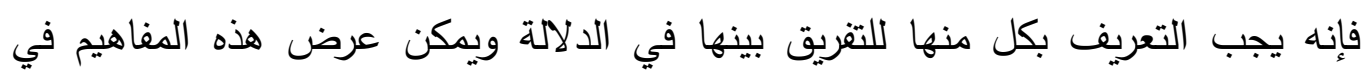

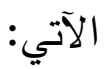




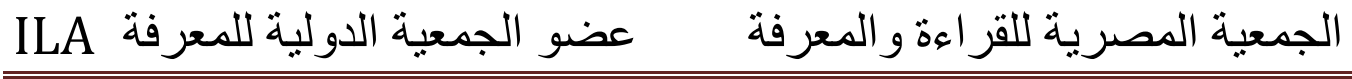

1

للخيال العلمي تقاطعاته مع أجناس أخرى. وهي تقاطعات مبنية على أساس بعينه، هو أن الخيال العلمي ليس جنساً خالصاً بالدرجة التي يفارق فيها جميع الأجناس الأدبية الأخرى. يتشرب الخيال العلمي شيئا من طاقاته من جميع التيارات والأساليب الأدبية، يتقاطع الخيال العلمي مع الفانتازيا واليوتوبيا على نحو خاصئ. أما الفانتازيا، فهو يتقاطع معها في الأسلوب والمضمون معا، وذلك أن الأحداث لا تفسر في الفانتازيا تفسيرا منطقياً كذلك يتماس الخيال العلمي مع الفانتازيا عندما تكون الحكاية في المستقبل البعيد أو أن تقع في عالم آخر مثل حرب النجوم حيث نجد عناصر مما وراء الطبيعة وأفكاراً علمية إضافية. ويميز هنا بين الخيال العلمي والفانتازيا بأن الخيال العلمي يوجد حيثما تعرض أشياء غير محتملة في الظاهر أو أشياء ذات طبيعة علمية، أو تقدم على نحو علمي وتسترعي التفكير، والتي لا يمكن أن تكون محتملة من حيث المبدأ في يوم من الأيام في عالمنا اليومي العادي. أما الفانتازيا. فالأمر معها يتعلق دائماً بأن تكون الأشياء المعروضة وليدة الخيال وغير محتملة في أي وقت. وعندما يختلط الخيال العلمي

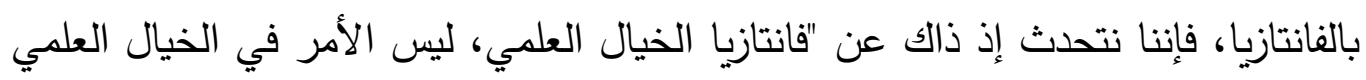

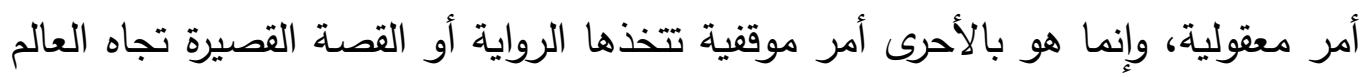
المعروض، ويدعي الخيال العلمي العلمية أو يتراءى بها، ومن ثم يستخدم بلاغة العلم. أما تقاطع الخيال العلمي مع اليوتوبيا، فهو أمر معروف في الأدبيات المعاصرة، يرتبط الخيال العلمي غالباً بمعالجة مظاهر التطور التقني والاجتماعي وتقع اليوتوبيا في بؤرة التخطيط للملامح الاجتماعية، تقوم اليوتوبيا على أفكار سياسية وفلسفية صريحة

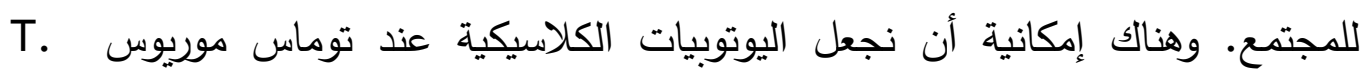
Morus 1623) من الخيال العلمي، لأنها تتطلق من نقطة زمنية تعالج فيها التقدم العلمي والتكنولوجي، وفي القرن التاسع عشر تحولت عشر تحولت اليوتوبيا مع الثورة الصناعية 


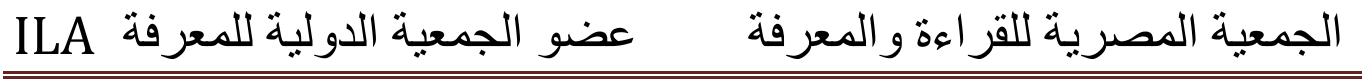

إلى المستقبل، وصارت القصص القصيرة مشتملة على عناصر يوتوبية نمطية، كانت اليوتوبيا الكلاسيكية قد انطلقت من بناء الدولة بناء هيكليا استاتيكيا، ولكن هذا التصور لم يتفق مع البناء الاجتماعي الديناميكي المعاصر، من ثم لم يكن غريبا أن تختفي في القرن العشرين اليوتوبيات الكلاسيكية، وأن تظهر الروايات اليوتوبية الساخرة التي راحت تنتقد

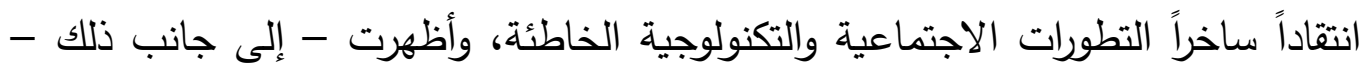
مفاسد الحياة اليومية والمخاطر التي تعتور العالم، صارت الرواية ترى اليوم خيالاً علمياً أو

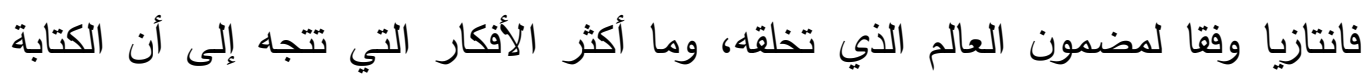
اليوتوبية لم يعد لها الآن مكان. وقد وصف بعضهم هؤلاء اليوتبيين بأنهم قوم محلقون فوق القة ولا علاقة لهم بالواقع، لقد بات وصف أناس بأنهم يوتوبيون يوحي بأنهم يفتقدون الثعور بالواقع وأن مشروعاتهم وأفكارهم مآلها الفشل، لأنها تتجاهل الامكانات العيانية. وقد انعكس هذا كله على نظرة الناس إلى المستقبل. ذلك أن المستقبل في نظر كثير من الناس لن يكون إلا صورة مطابقة للحاضر ، ربما كانت أفضل في بعض الأحيان، ولكنها أسوأ على وجه العموم. (جاكوبي، راسل ، 2001، 98)، (تحمد العبد، 2007، 28).

2 - أدب الخيال العلمي والأسطورة:

تلتقي السطورة مع أدب الخيال العلمي في عدة نقاط لعل من أهمها الغرائبية والإدهاش، فهذا الأدب غنى بالأحداث الغرببة والمدهثة التي لا تتسجم مع مقتضيات

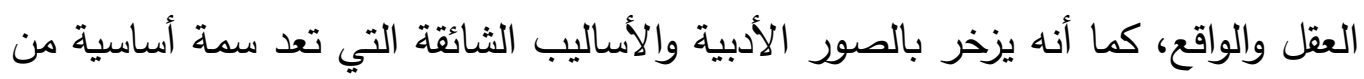

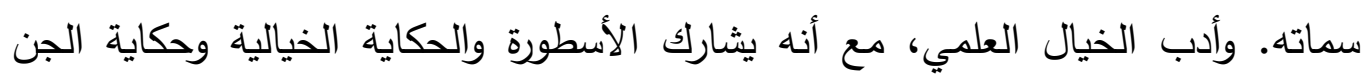

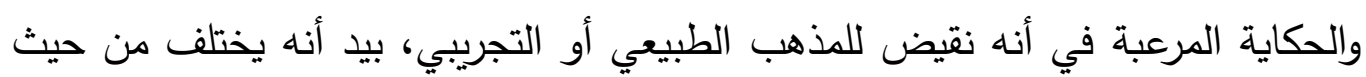
المنهج والوظيفة الاجتماعية.

إن تعريف الأسطورة يزيد المهمة في تبيان الفروق بينها وبين أدب الخيال العلمي ، فعلى الرغم من عدم إجماع النقاد على تعريف موحد للأسطورة، فإنهم جاؤا بالبنود لئن 


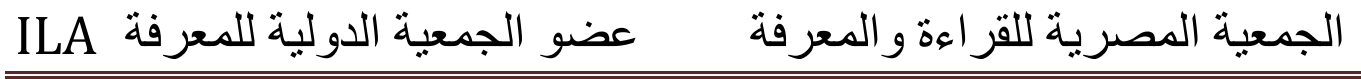

العريضة التي تتبني عليها الأساطير، الأمر الذي يساعد في إثبات الفروق بين هذين

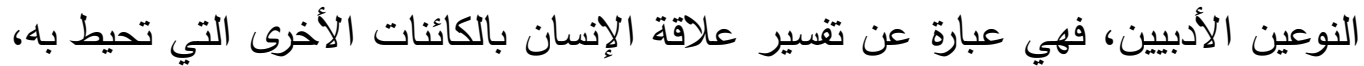
فالأسطوة هي الدين وشعائره، والتاريخ وحوادثه، والفلسفة ومجالاتها، والكون جميعه عند لإنديز القدماء، وأهم ما يميز الأسطورة من أدب الخيال العلمي الآتي: لا تتحدث الأسطورة إلا عن أشياء كائنة أو موجودة فعلاً ، لتقوم بعد ذلك بإسناد وجود تلك الأشياء إلى كائنات إلهية القدرة، أما أدب الخيال العلمي فإنه يلتزم الحديث عن أشياء موجودة بالفعل، بل يتعدى ذلك إلى وصف أشياء خيالية غير مخلوقة فعلاً في الطبيعة، ولا ينسب الخيال العلمي غالباً تلك الأثياء إلى كائنات إلهية، وإنما يعيدها إلى أسباب بشرية وعلمية خالصة. أبطال الأسطورة كائنات فوق الطبيعة، ويقوم هؤلاء الأبطال بالمآثر في أزمان سحيقة بينما ينحدر أبطال أدب الخيال العلمي إلى أصولهم الدنيوية البشرية، وما أعمالهم الخارقة التي يقومون بها سوى قدرات منحتها لهم الآلات والمخترعات العلمية الحديثة. تكثف الأسطورة عن مضدونها المقدس لاعتمادها على كائنات خارقة للطبيعة تقوم بعمليات الخلق وإبداع الأشياء، ولا يمكن النظر إلى الأسطورة على أنها نشاط أدبي إبداعي فحسب، بل هي نمط ديني يكتب القداسة ويقدم الأنموذج الأمثل للحياة الأفضل بالمقابل، فإن أدب الخيال العلمي لا يكتسب أية درجة من درجات القداسة، وبالتالي فهو لا يشكل أنموذجا لحياة أيا كانت هذه الحياة. تروي الأسطورة تاريخاً مقداً يبدأ من لحظة الخلق، وينتهي عند لحظة الوجود، ويكتسب هذا التاريخ درجة الصحة المطلقة ، وعادة ما يدعم بالثواهد والتفاسير المدهة التي تتوالى بكثافة بدون أن تمنح العقل فرصة لكي يسأل: "وكيف تم ذلك؟" أما الخيال العلمي فليس معنيا بالتاريخ إلا إذا كان يخدم غرضه الأدبي ويقدم له مادة 


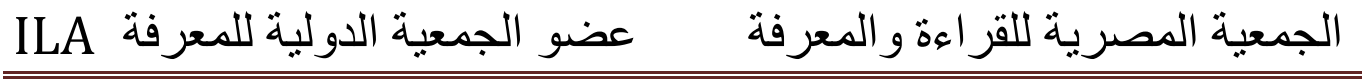

يحلق من خلالها في أجواء الخيال، وهو بهذا ينفي عن نفسه أهم صفة من صفات

التاريخ المقدس وهي "الصحة المطلقة".

3

ظل النقاد العرب يخلطون بين مصطلح أدب الخيال العلمي ومصطلح القصة العلمية أو الأدب العلمي ، فقد استخدم هذان المصطحان بوصفهما مترادفين ولهما دلالة

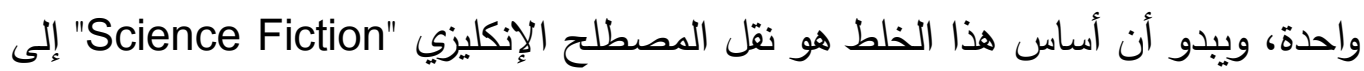
العربية تحت مسميات متباينة، إذ ترجم إلى "القصص العلمي التصوري" أو "الأدب التبات

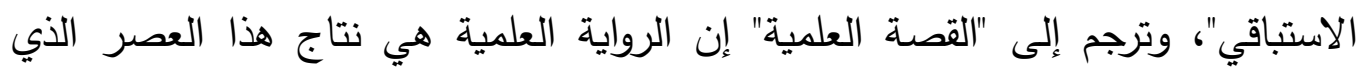
أصبح للعلوم فيه أهمية قصوى لم تكن لها في عصور سابقة، أي أن يشير بـ "الرواية

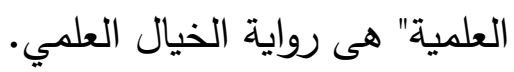

ويعود الفرق بين قصة الخيال العلمي والقصة العلمية إلى هدف كل منهما، فالقصة العلمية تتخذ من الوقائع والقوانين العلمية الثابتة التي لا خلاف عليها موضوعاً

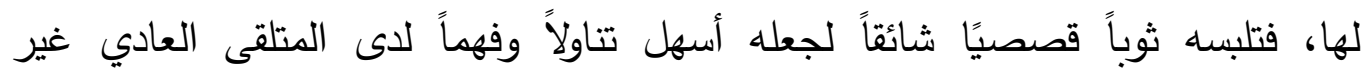

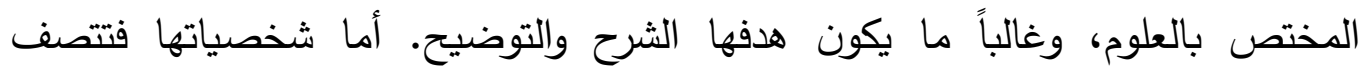
بالتاريخية أو الوثائقية ويغلب أن تكون من العلماء المرموقين كابن سينا والرازي وابن الهيثم ونيوتن وأنثاتين بعد إجراء تحويرات قصصية مناسبة على هذه الثخصيات باستغلال أحداث درامية من حياتهم العلمية أو الخاصة.

وقد تتميز القصة العلمية بشخصنة الأشياء بغية شرحها وتبسيطها، فقد تصور حواراً بين الذرات أو تقدم الفيروسات أو تجعل من الكواكب كائنات عاقلة... ويمكن إظهار الفرق بين القصة العلمية وقصة الخيال العلمي في هذا المجال بإيراد مثال ، فالكاتب الذي يصور حرباً بين الكريات البيض وبين الجراثيم في جسم الإنساني مثلاً ، هو كاتب قصة 


\section{الجمعية المصرية للقر اعة والمعرفة عضو الجمعية الدولية للمعرفة ILA}

علمية ، أما الكاتب الذي يصور دخول جرثومة غريبة في جسم إنسان لتحوله إلى كائن آخر مختلف فهو كاتب خيال علمي. 4 - - أدب الخيال العلمي والخرافة:

يمكن النظر إلى الخرافة بوصفها: "عبرة تحكي تتستر وراء مواقف بسيطة"، بمعنى

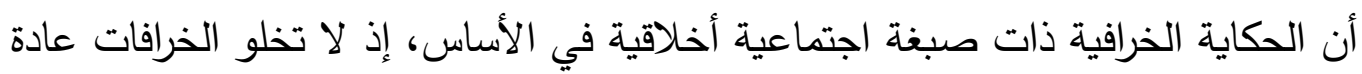

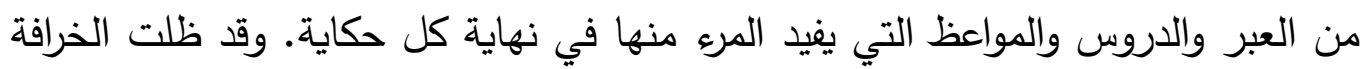

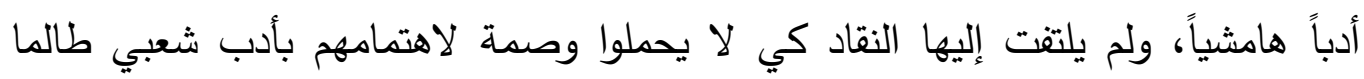

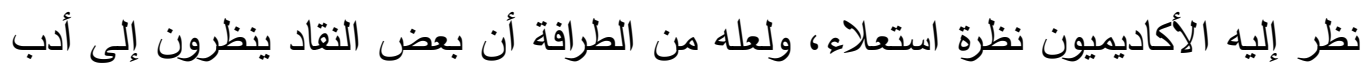

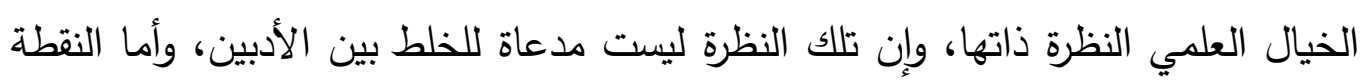

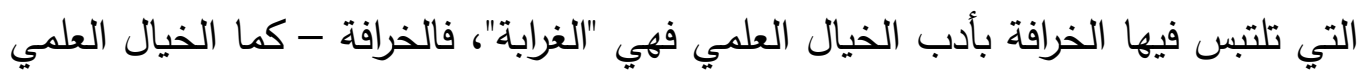
- تعتمد في سردها على أحداث تثير الدهثة والعجب لدى المتلقى لتثد انتباهه إليها فلا

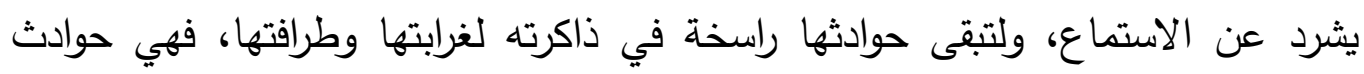
استثنائية ودروسها تستحق الكتابة.

على أن لكل من الخرافة وأدب الخيال العلمي خصائص وسمات تحول دون

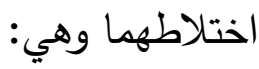

الخرافة نفسها تحكي عند شعبين مختلفين وقد اصطبغت تفاصيلها بصبغة المحلية لاى كل منهما، أما أدب الخيال العلمي فقد ظهر أدبا مكتوبا ولم تتداوله الثعوب على نطاق واسع كما هي الحال في الخرافة، بل اقتصر انتثاره لدى الأمم المتقدمة أو الثعوب التي أوتيت حظاً من العلم.

تركز الخرافة على مغزى أخلاقي فهي ترمي إلى هدف أو عبرة تمجد عملاً

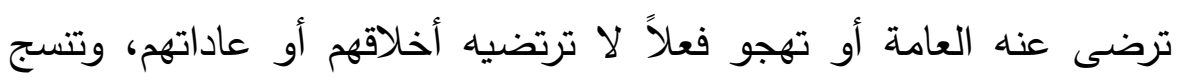




\section{الجمعية المصرية للقر اعة والمعرفة عضو الجمعية الدولية للمعرفة}

الحكاية الخرافية خيوطها البسيطة لتلتقي في نقطة واحدة هي "العبرة" بالمقابل فإن قصة الخيال العلمي لا تضع العبرة أو الموعظة في الدرجة الأولى من أولوياتها، وإن كان لأدب الخيال العلمي مبادئه وأخلاقياته كأي أدب إنساني آخر

شخصية البطل في الأدب الخرافي شخصية شعبية بسيطة تتسم بكل الصفات المحبوبة من شجاعة وجرأة وتضحية وكرم أما بطل الرواية في الخيال العلمي فغالباً ما يكون شخصية ذات مكانة علمية عالية، وغالباً ما تكون شريرة وعدوانية عندما تستخدم العلم لأغراض أنانية وتدميرية. لا تطالب الحكاية الخرافية مستمعيها أو قراءها بثقافة علمية عالية أو معرفة بفرضيات وقوانين العلوم، بل تتوجه إلى جمهور يتصف بالثعبية والبساطة، أما رواية الخيال العلمي فإنها تتطلب من قارئها قدراً معينا من المعرفة والإطلاع على العلوم ومنجزاتها بمستويات مختلفة بين عمل وآخر • كثيراً ما تتدخل المصادفة والقدر في الأدب الخرافي ليحرفا مسار الحكاية أو الحدث، وقد تقتحم أو الحدث، وقد تقتحم عوامل غير بشرية مجريات الأحداث لإثارة الدهشة والغرابة، بينما تقل المصادفات في أدب الخيال العلمي الجيد.

$$
5
$$

قصة الرعب تعتمد على إثارة الفزع لدى القارئ بتصوير الأشباح والأماكن

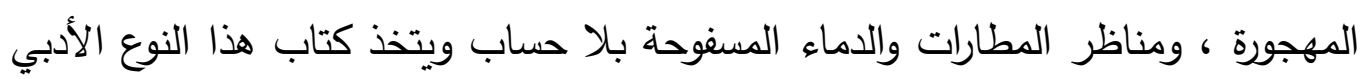
من خبرتهم بأعماق النفس البشرية مساعداً لتحريك غريزة الخوف لدى المتلقى بدفعهم القارئ إلى التحسب والإشفاق على البطل ورفع درجة هذا الإشتقاق إلى منتهاه عند ذلك يتم تعريض البطل فجأة لخطر مجهول يصعب الانفكاك منه، أما وجه الالتباس بين 


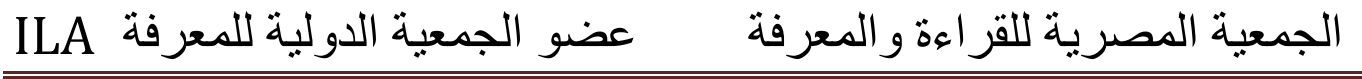

القصة المرعبة وقصص الخيال العلمي فهو استخدام بعض خصائص أدب الخيال العلمي في قصص الرعب، كما أن أدب الخيال العلمي هو الآخر قد يستعين أحياناً بشحنات الخوف التي أتقنتها القصة المرعبة، ويقترب الأدب المرعب من أدب الخيال العلمي عندما

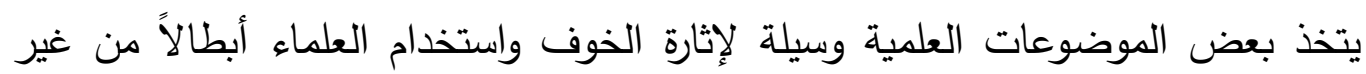
أخلاقيين غالباً لمثل هذه الأعمال الأدبية، كما يلامس أدب الخيال العلمي المرعب عندما لإدها يتحدث عن المخلوقات المرعبة القادمة من كواكب مجهولة، أو عندما يتكلم عن آبار

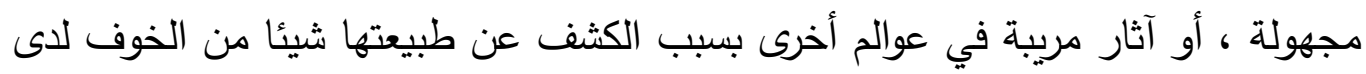

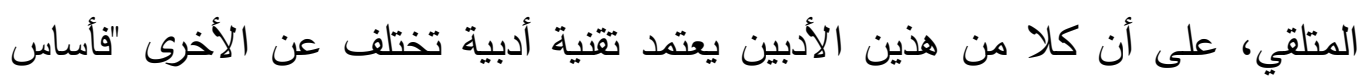
الأدب العجيب هو الرعب، ويستبدل به في الخيال العلمي المفاجأة والإدهاش".

\section{خلاصة وتعقيب:}

الحديث عن الخيال العلمي باعتباره المتغير المستقل يثير إلى مجموعة من

$$
\text { المعطيات التي تفيد في مجال تنمية مهارات الإبداع من حيث: }
$$

1. الخيال العلمي يختلف في دلالته عن الخيال الأدبي، والقصص العلمية والفانتازيا واليوتوبيا، والأسطورة، وحكايات الرعب، وعليه يتوجب اختيار أدب الخيال العلمي من قصة أو مسرحية أو فلم بمواصفات هذا الأدب وقواعده. 2. تفاطعات الأجناس الأدبية الخيال العلمي في بعض مميزاته ، هي تقاطعات مبنية على أساس بعينه هو أن الخيال العلمي ليس جنسا خاصاً بالدرجة التي يفارق فيها جميع الأجناس الأدبية الأخرى، وهي مسلمة لا يأخذ بها البحث الحالي، وعليه يصبح الخيال العلمي جنسا أدبياً له مقوماته وأصوله. 


\section{ILA الجمعية المصرية للقر اءة والمعرفة عضو الجمعية الدولية للمعرفة}

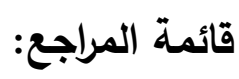

1. أحمد سعيد وياسر فوزي (2015). الخيال والتفكير البصري أساس لبناء تعلم بصري قائم على الجمع بين الواقع والصورة الممثلة له، مصر، جمعية أمسيا.

2. بثينة عبد الحي أبو بكر (2017). الخيال العلمي أدب المستقبل ، جامعة أسوان، مجلة كلية الأداب.

3. حسن شحاته وليلى معوض (2018). التعليم للإبداع وصناعة المبدعين، القاهرة، الدار المصرية اللبنانية.

4. حمادة الثريف ومنيرة الدلمي (2018). تتمية الخيال العلمي ضرورة ملحة في المؤسسات التعليمية العربية "دراسة وصفية"، الجزائر، مجلة جيل للعلوم الإنسانية

$$
\text { والاجتماعية. }
$$

5. راجي عنايت (1995). الإبداع والمستقبل خواطر وآراء للتأمل حول الإبداع والمستقبل، القاهرة، مجلة مستقبل التربية العربية.

6. رؤوف وصفي (1999). أدب الخيال العلمي، بغداد، دائرة الثؤون الثقافية. 7. روبرت أندروس وجورج ستانسيو (1998). العلم في منظورة الجديد ، الكويت، سلسلة عالم المعرفة.

8. شاكر عبد الحميد (2009). الخيال من الكهف إلى الواقع الأفراضي، الكويت، عالم

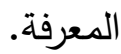

9. شاكر عبد الحميد وعبد اللكيف خليفة (2000). دراسات في حب الاستطلاع والإبداع والخيال، القاهرة، دار غربب.

10. طالب عمران (2015). الخيال العلمي في الأدب ، الجمهورية العربية السورية، مجلة الموقف الأدبي. 


\section{الجمعية المصرية للقر اءة والمعرفة عضو الجمعية الدولية للمعرفة}

$$
\text { 11. كرستين دور هام (2004). تتمية الإبداع عند الأولاد ، ترجمة: فاتن صبح، بيروت، دار }
$$

12. ليزا توتلي (2008). فن كتابة الفانتازيا والخيال العلمي، الثقاهرة، الدار المصرية اللبنانية. 13. ليندا جين شيفرد (2004). انثوية العلم ، العلم من منظور الفلسفة النسوية، الكويت، سلسلة

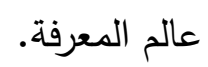

14. محمد السيد العبد (2007). الخيال العلمي استراتيجية سردية ، مصر ، مجلة فصول.

15. محمود قاسم (1997). الخيال العلمي مصطلحات واسماء ، القاهرة، الدكتبة الأكاديمية.

16. نهاد شريف (1997). الدور الحيوي لأدب الخيال العلمي، القاهرة، المكتبة الأكاديمية.

17. يعقوب نشوان (1993). الخيال العلمي لاى أطفال دول الخليج العربي، الرياض، مكتب

$$
\text { التربية العربي لدول الخليج. }
$$

18. يوسف الثاروني (2002). الخيال العلمي في الأدب العربي ، القاهرة، الهيئة المصرية العامة للكتاب.

19. Al Wadi, H. (2001). The Effects of Using Creative Commercial School Learning English on Third Secondary Commercial School Students Creative Skills, Educational Science Journal, 4 (3), 246-247.

20. Amabile, L. (2006). Creativity and Innovation. Harvard, Harvard Press Inc.

21. Brana, P. (1991). Promoting Creative Confrontation. Journal of Computer Assisted Learning , 7 (2).

22. Daignault, L. (2003). Children's Creative Musical Thinking Within the Context of a Computer - Supported Improvisational Approach to Composition. Doctoral Dissociation, Northwestern University, Boston.

23. David, A. Kalz (1999). Science and science fiction with emphasis on chemistry and science fiction, science and science fiction national science teachers Association national meeting, Boston, M. A., March. 
24. Laprise, S., \& Winirch, C. (2010). The Impact of Science Fiction Films on Student Interest in Science (Electronic Version). Journal of College Science Teaching, 40, (2).

25. Michalok, M. (2002). Four Steps Towards Creative Thinking, Futurist, Hournal, 34 (3).

26. Runco, M. (1997). The Creativity Research Handbook Hampton Press Inc. New Rersey.

27. Terence W. Cavanaugh, Cathy Cavanaugh (2004): Teach science with science fiction films: A guide for teacher and library Media specialist "Published by Longworth Publishing", Inc 480 East Wilson Bridge Roaf, Site L.

28. Terence, W. Cauanaugh, Gathy Cavanaugh (2004). Teach science with science fiction films: A guide for teachers and library, media special is, published by linwarth publishing Inc., 4890 Est Wilson Bridge Roadm suite 1

29. Laprise, S., \& Winirch, C. (2010). The Impact of Science Fiction Films on Student Interest in Science (Electronic Version). Journal of College Science Teaching, 40, (2).

30. Walton, L. (2009). Creativity Among Gifted Students, Journal of Education, I (1), 200-256.

31. Weir, C. (2000). Using Questions to Fuse Thinking in Middle School Remedial Readers. Journal of Adolescent and Adult Literacy, 41 (5), 58-465. 